\title{
Modelagem numérica da região costeira de Santos (SP): Circulação de maré
}

\author{
(Numerical modeling of the coast region of Santos (SP): tidal circulation)
}

\author{
Joseph Harari ${ }^{1} \&$ Ricardo de Camargo ${ }^{2}$ \\ ${ }^{1}$ Instituto Oceanográfico da Universidade de São Paulo \\ (Caixa Postal 66149, 05315-970 São Paulo, SP, Brasil) \\ ${ }^{2}$ Instituto Astronômico e Geofísico da Universidade de São Paulo \\ Departamento de Ciências Atmosféricas \\ (Rua do Matão, 1226 - 05508-900 São Paulo, SP, Brasil)
}

- Abstract: The Princeton Ocean Model (POM) was implemented for the coastal region of Santos $\left(46^{\circ}-47^{\circ} \mathrm{W}, 23^{\circ} 40^{\prime}-24^{\circ} 30^{\prime} \mathrm{S}\right)$, with a regular grid of resolution $\cong 1 \mathrm{~km}$ and 11 sigma levels in the vertical. The model was used in tidal simulations, with the specification of the correspondent oscillations at the boundaries, computed through cotidal maps of the shelf. The model runs considering separately the lunar and solar principal components (M2 and S2), for 5 days each, and the 9 principal tidal constituents composed, for 31 days. The tidal analysis of the resulting time series allowed the obtention of maps with the cotidal lines and the axes of the surface current ellipses. These maps indicate the characteristics of the propagation of the tidal waves in the modeled area, with the spatial distributions of their elevations and currents. The most important aspects discussed in this study are: the contrast of the circulation intensities, between the deeper region and the internal shallow areas; the marked differences of current intensities in both sides of Santos Bay; the currents convergence / divergence in São Vicente and Bertioga Channels; tidal assimetries in the shallow regions; and the counterclockwise rotation of the currents in the coastal area. The model can be used for operational predictions of tides and tidal currents in the study area.

- Resumo: Foi implementado o Princeton Ocean Model (POM) para a região costeira de Santos $\left(46^{\circ}-47^{\circ} \mathrm{W}, 23^{\circ} 40^{\prime}-24^{\circ} 30^{\prime} \mathrm{S}\right)$, com grade regular de resolução $\cong 1 \mathrm{~km}$ e 11 níveis sigma na vertical. O modelo foi utilizado em simulações de maré, com a especificação das correspondentes oscilações nos contornos, calculadas com base em mapas cotidais da plataforma. $\mathrm{O}$ modelo foi processado considerando isoladamente as componentes principais lunar e solar (M2 e S2), cada qual por 5 dias, e com as 9 principais componentes de maré conjuntamente, por 31 dias. As análises de maré das séries temporais de resultados possibilitaram a composição de mapas com linhas cotidais e eixos das elipses de correntes de superficie. Esses mapas indicam as características da propagação das ondas de maré na área modelada, com as distribuições espaciais de suas elevações e correntes. Os aspectos de maior interesse no estudo realizado são: o contraste das intensidades das circulações, entre a parte mais profunda e regiões internas rasas; as marcantes diferenças de intensidade de correntes nos dois lados da Baía de Santos; a convergência / divergência das correntes nos Canais de São Vicente e de Bertioga; assimetrias de maré nas regiões rasas; e rotação anti-horária das correntes na área costeira. $\mathrm{O}$ modelo pode ser utilizado em previsões operacionais de marés e correntes de maré na área de estudo.

- Descriptors: Hydrodynamical numerical modelling; Sigma vertical coordinate; Tides; Tidal currents; Cotidal maps; Current ellipses; Tidal predictions; Coastal region of Santos (SP, Brazil).

- Descritores: Modelagem numérica hidrodinâmica; Coordenada vertical sigma; Marés; Correntes de maré; Mapas cotidais; Elipses de correntes; Previsões de maré; Região costeira de Santos (SP, Brasil). 


\section{Introdução}

A região considerada no presente estudo é limitada pelas latitudes de $23^{\circ} 40^{\prime}$ e $24^{\circ} 30^{\prime} \mathrm{S}$ e pelas longitudes de $46^{\circ}$ e $47^{\circ} \mathrm{W}$, tendo ao centro a cidade de Santos e incluindo diversos municípios do litoral do Estado de São Paulo, como Peruíbe, Itanhaém, Mongaguá, Praia Grande, São Vicente, Cubatão, Guarujá e Bertioga; a área modelada é localizada na Figura la e apresentada em detalhes, com sua batimetria, nas Figuras $1 \mathrm{~b}$ e $1 \mathrm{c}$, onde os valores de profundidade variam de 2 a $53,5 \mathrm{~m}$. Esta região constitui um dos polos de desenvolvimento do país, possuindo uma grande população $\mathrm{e}$ diversas atividades econômicas de grande porte, como por exemplo a pesca, o transporte marítimo, a indústria $\mathrm{e}$ o lazer. A área contém ecossistemas de enorme importância econômico-ambiental, como o Canal de São Vicente, o Canal de Bertioga e o Canal do Porto de Santos, atualmente o maior porto da América do Sul.

De forma similar a outras grandes áreas litorâneas do país, a região estudada possui diversos problemas de difícil solução, como por exemplo: a poluição marítima, causada pelos dejetos industriais e dos centros urbanos; o efeito de intrusões salinas no abastecimento de água doce; e a segurança de navegação, considerando os navios de grande porte que utilizam o Porto de Santos. O conhecimento detalhado da circulação marítima na área costeira citada pode oferecer subsídios ao melhor equacionamento desses problemas e na obtenção de suas soluções.

Muitos trabalhos oceanográficos foram desenvolvidos na plataforma continental adjacente à área de interesse do presente estudo; entretanto, nesta área específica, o número de trabalhos realizados é relativamente reduzido.

As principais pesquisas científicas referentes à plataforma, e que apresentam relação com este trabalho, são a seguir listadas. Mesquita et al. (1979) analisaram as correntes na plataforma entre Cabo Frio e Cananéia, como parte de um projeto de hidrodinâmica costeira que proporcionou um significativo número de observações na plataforma sudeste do Brasil (Mesquita, 1983). No âmbito deste projeto, foram efetuadas medições pelágicas de maré, as quais foram analisadas por Mesquita \& Harari (1987), e cujos resultados foram utilizados na implementação de um modelo numérico da circulação na plataforma, apresentado em Harari (1985). Neste modelo, são consideradas as circulações devidas às marés e aos efeitos meteorológicos de superfície, cujas simulações de maior interesse se encontram em Harari \& Camargo (1994) e em Camargo \& Harari (1994). Castro Filho (1985) também desenvolveu um modelo de circulação para a plataforma sudeste do Brasil, com ênfase nas frequências abaixo das de maré. Nos estudos hidrográficos da parte norte da plataforma, se tem os trabalhos de Miranda (1982) e de Castro Filho et al. (1987), com a caracterização das massas d'água e suas variabilidades sazonais. Stech \& Lorenzzetti (1992) analisaram a resposta da plataforma à passagem de frentes frias, com um modelo de elementos finitos. Finalmente, Cirano \& Campos (1996) reproduziram a circulação das massas d'água, a partir de $50 \mathrm{~m}$ e incluindo áreas oceânicas profundas adjacentes, através de uma simulação diagnóstica baseada em modelo de coordenada sigma.

Para a área específica de estudo do presente trabalho, em relação à circulação costeira, podem ser citadas as seguintes publicações científicas: Mesquita (1974) analisou dados de temperatura da água do mar; Sondotécnica / INPH (1977) efetuaram extensivo levantamento de dados hidráulico - sedimentológicos no estuário santista; Yassuda (1991) modelou o transporte de sedimentos no Canal Principal do Estuário de Santos; Alfredini (1994) elaborou uma revisão dos principais estudos ambientais efetuados na Baixada Santista; e Harari \& Camargo (1995) analisaram dados de maré do Porto de Santos, medidos no período de 1944 a 1989.

Atualmente, se encontram em fase de execução programas de amostragens na região de interesse do presente trabalho, a saber: levantamentos oceanográficos são realizados pela Fundação de Estudos e Pesquisas Aquáticas - FUNDESPA (1996, 1997); está sendo implantado um sistema automatizado de coleta de dados ambientais no Porto de Santos (Cacciari \& Harari, 1996*); e estão sendo instaladas estações de medições oceanográficas na costa, em projeto apoiado pela Fundação de Amparo à Pesquisa do Estado de São Paulo - FAPESP, conforme descrito em Harari \& Cacciari (1995).

No contexto científico acima exposto, no qual modelos da plataforma foram implementados e medições costeiras foram analisadas, se tornou possível a implantação deste modelo de alta resolução da região costeira de Santos. Para tanto, foram utilizados os resultados do modelo de plataforma de Harari \& Camargo (1994), para a especificação das condições de contorno laterais; as amplitudes e fases do contorno foram adicionalmente corrigidas, com base na comparação de resultados preliminares do modelo (Harari, 1996**) com as análises dos registros do Porto de Santos, efetuadas por Harari \& Camargo (1995). Para a implantação do modelo, muito contribuiu o acesso a recursos computacionais de alta qualidade, no Instituto Oceanográfico da USP, bem como a disponibilidade de softwares em rede mundial.

(*) Cacciari, P. L. \& Harari, J. 1996. Implementação de um sistema automatizado de coleta de dados ambientais no Porto de Santos (SP). In: SIMPÓSIO SOBRE OCEANOGRAFIA, 3. Resumos. São Paulo, IOUSP, p. 372

(**) Harari, J. 1996. Resultados preliminares da modelagem numérica da propagação das ondas de maré na região costeira de Santos (SP). In: SIMPÓSIO SOBRE OCEANOGRAFIA, 3. Resumos. São Paulo, IOUSP. p. 388. 
a

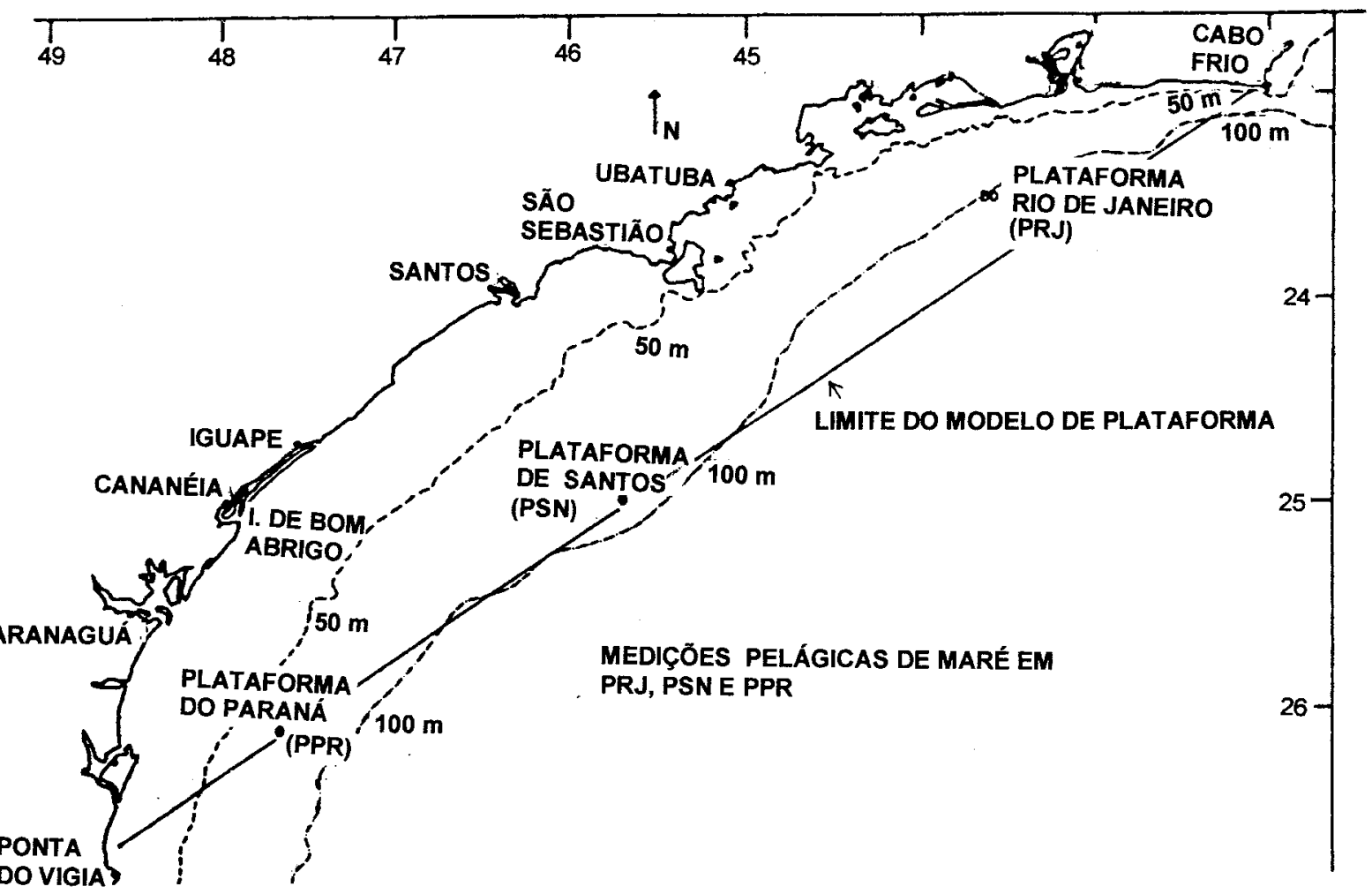

b

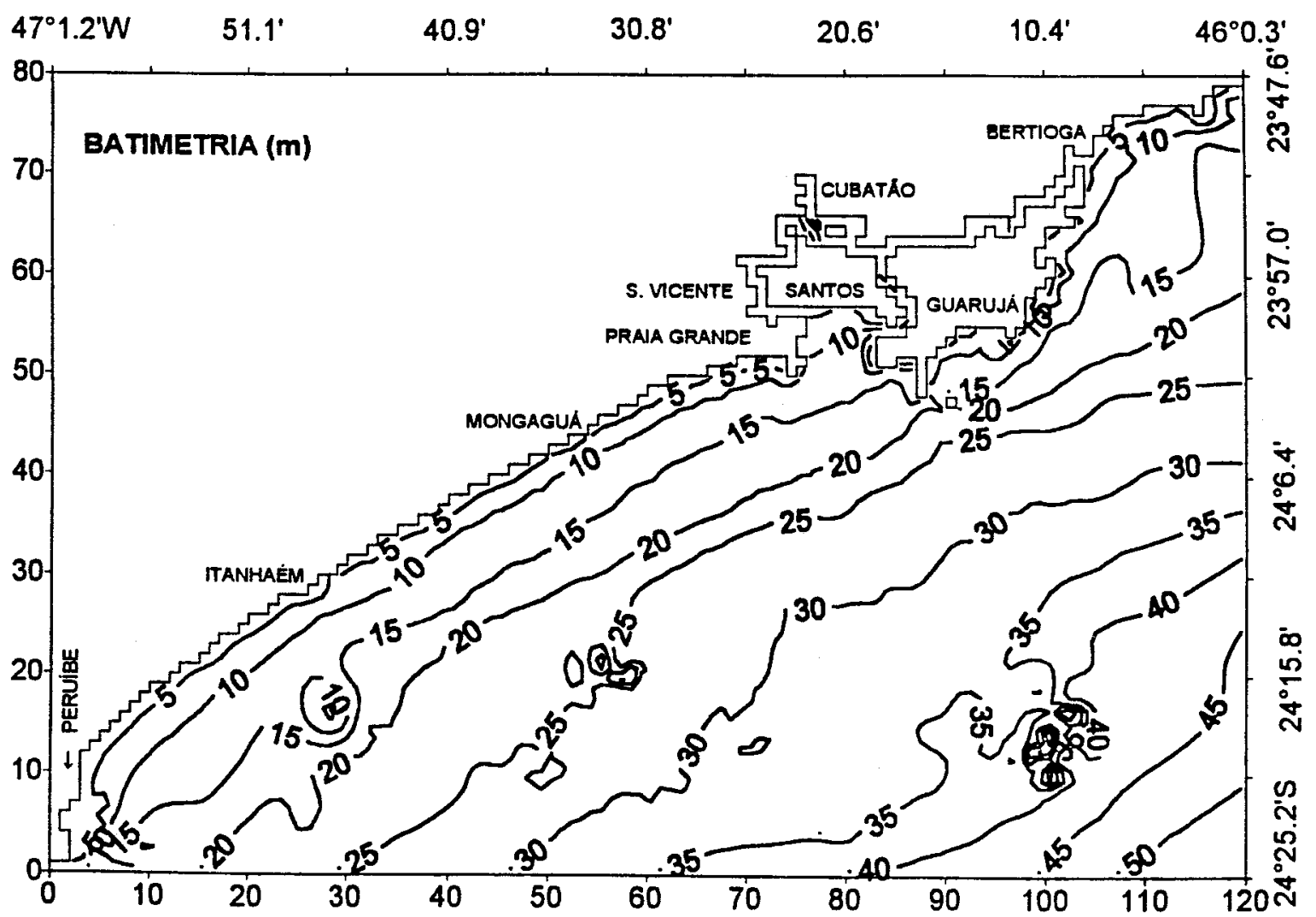

Fig. 1. Mapas geográficos com a localização da área modelada (a). seu detalhamento e batimetria - para a região completa (b) e áreas interiores rasas (c). 


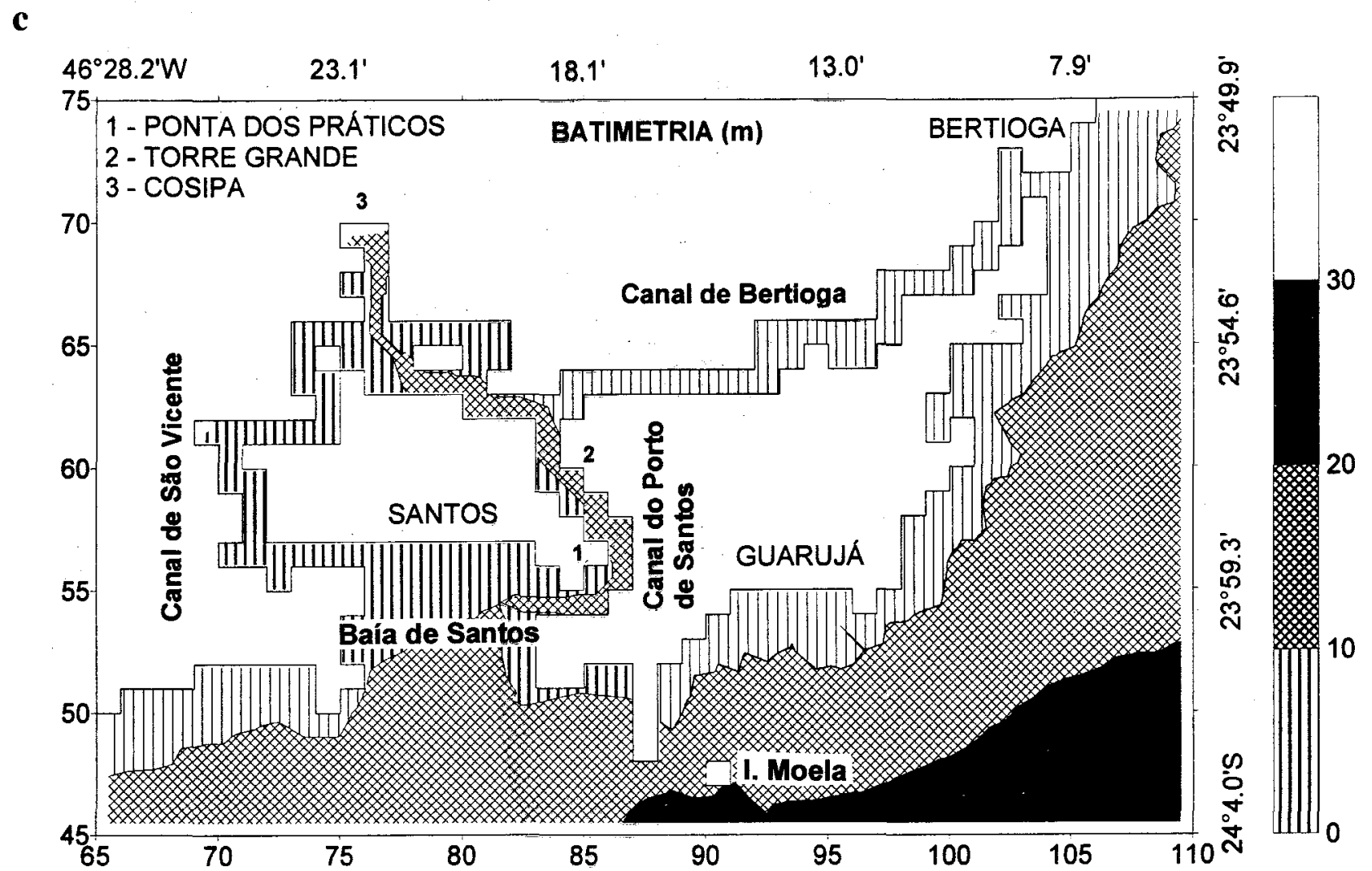

Fig. 1. Cont.

Neste primeiro trabalho de modelagem em alta resolução da área costeira de Santos, o interesse foi restrito à circulação de maré. Numa segunda etapa, circulações devidas a efeitos meteorológicos e ao campo de densidade deverão ser incluídas, contando com o apoio dos programas de medições acima citados. $\mathrm{E}$ com o desenvolvimento das técnicas de informática, modelos de resolução maior poderão ser adotados, tanto para a circulação de maré, como também para a circulação geral da área.

É importante notar que o objetivo científico principal deste trabalho foi o de obter um conhecimento maior da propagação das ondas de maré e da distribuição espacial das elevações e das correntes de maré na área costeira de Santos. Paralelamente a este conhecimento científico, com a modelagem implementada, se tem um suporte muito útil para diversas aplicações técnicas e de engenharia, como por exemplo $\mathbf{o}$ controle da poluição, a estimativa de intrusões salinas, o dimensionamento de obras, etc ... Por outro lado, os resultados obtidos constituem apenas uma etapa intermediária da modelagem numérica hidrodinâmica da área de interesse, cuja etapa final deverá considerar a inclusão de forçantes meteorológicas e de densidade na circulação, juntamente com as marés. Nesse caso, o objetivo científico deverá contemplar o interesse no conhecimento da propagação dos distúrbios de origem meteorológica e do campo de densidade na área, bem como sua interação com as marés. Para a modelagem da circulação geral, informações sobre a circulação de baixa frequência e a caracterização de massas d'água, tanto da área específica deste trabalho, como também de regiões próximas, deverão ser muito úteis. Deve-se ressaltar a grande dependência da próxima etapa de modelagem com medições : oceanográficas; por outro lado, as aplicações técnicas e de engenharia da modelagem, acima citadas, deverão ser melhor contempladas.

\section{Material e métodos}

Foi implementado o Princeton Ocean Model (POM) para a área de estudo, desenvolvido por Blumberg \& Mellor (1987) e apresentado em detalhes por Mellor (1993). Este modelo permite determinar a evolução temporal dos campos de elevação, temperatura, salinidade, densidade, correntes e transportes, a partir da especificação da batimetria, condições meteorológicas na superfície e condições oceanográficas nos contornos abertos. 
As principais características da versão do POM utilizada são as seguintes: é tridimensional, não linear, com as equações hidrodinâmicas completas escritas na forma de fluxo; adota as aproximações de Boussinesq e hidrostática; a solução na vertical é baseada em coordenadas sigma, que acompanham o relêvo; se considera um fechamento turbulento de $2 \mathrm{a}$. ordem para os coeficientes de viscosidade e de difusão na vertical, com equações para a energia cinética turbulenta e para a escala do comprimento de turbulência; a viscosidade e difusão horizontais tem parametrização do tipo Smagorinsky; nas equações se tem a separação dos modos externo e internos, cuja evolução temporal é determinada com passos de tempo diferentes; e na parte numérica, o esquema de leapfrog é utilizado para a integração no tempo e na horizontal, enquanto que a integração na vertical é efetuada com um esquema implícito.

Os detalhes mais importantes da formulação matemática do modelo serão a seguir fornecidos (Blumberg \& Mellor, op. cit.). O primeiro aspecto característico do POM se encontra na substituição da coordenada vertical linear $\mathrm{z}$ pela coordenada $\sigma$, através da relação que leva em conta a elevação da superficie $\eta$ e a profundidade média $D$ :

$\sigma=(\mathrm{z}-\eta) /(\mathrm{D}+\eta)$

As equações do movimento possuem os termos de aceleração local, advectiva e de Coriolis, gradientes de elevação e de pressão, e difusões horizontal e vertical. As equações de conservação do calor e da salinidade consideram variações locais e advectivas, difusões horizontais e verticais, além de fontes ou sorvedouros das propriedades. Outro aspecto peculiar do POM é que os coeficientes de difusão vertical de momento e de temperatura / salinidade, $\mathrm{K}_{\mathrm{M}}$ e $\mathrm{K}_{\mathrm{H}}$, são calculados de acordo com o modelo de turbulência de Mellor \& Yamada (1974, 1982); nessa formulação, são consideradas equações para a energia cinética turbulenta $\left(\mathrm{q}^{2} / 2\right)$ e para a escala de comprimento da turbulência (L); nas equações para $q^{2} / 2$ e $q^{2} L$, se tem os termos de variação local e advectiva, difusão, produção por cisalhamento, produção por flutuação e dissipação. Dessa forma, se tem as expressões:

$$
\mathrm{K}_{\mathrm{M}}=\mathrm{S}_{\mathrm{M}} \mathrm{Lq} \quad \mathrm{K}_{\mathrm{H}}=\mathrm{S}_{\mathrm{H}} \mathrm{Lq}
$$

onde $S_{M}$ e $S_{H}$ são fatores de estabilidade, tabelados por Mellor (op. cit.). Além da difusão vertical, o modelo possui a difusão horizontal, onde a formulação de Smagorinsky foi adotada, fornecendo o coeficiente $A_{M}$ a partir de uma constante $C$, dos espaçamentos de grade $\Delta \mathrm{x}$ e $\Delta \mathrm{y}$ e das derivadas das componentes de corrente $\mathrm{u}$ e $\mathrm{v}$ em relação às coordernadas x e y (denotadas com subscritos):
$A_{M}=C \Delta x \Delta y\left\{u_{x}^{2}+\left(v_{x}+u_{y}\right)^{2} / 2+v_{y}^{2}\right\}^{1 / 2}$

Como o modelo utiliza a técnica de separação de modos, as equações da continuidade, do momento e hidrostática são verticalmente integradas; o conjunto de equações barotrópicas é integrado no tempo com um passo de tempo pequeno, enquanto que o conjunto completo de equações tridimensionais utiliza um passo bem maior; a cada certo número de cálculos 'barotrópicos', se tem um cálculo 'baroclínico'. O modo baroclínico proporciona o cálculo da fricção no fundo, de integrais verticais da densidade e de variâncias verticais da velocidade horizontal ao cálculo do modo barotrópico; este, por sua vez, fornece a elevação da superfície ao cálculo do modo baroclínico.

Nas equações tridimensionais do movimento, a condição de não escorregamento no fundo é imposta a partir de um perfil logarítmico das velocidades na camada limite do fundo, no qual se considera os parâmetros de velocidade friccional no fundo $\mathrm{u}_{*} \mathrm{e}$ de comprimento da rugosidade $\mathrm{z}_{0}$. A velocidade friccional no fundo é calculada a partir dos valores de corrente determinados pelo modelo no penúltimo nível sigma de profundidade.

No POM, a integração numérica no tempo, pelo esquema de leapfrog, pode apresentar divergência das soluções nos passos de tempo pares e ímpares; a remoção dessa eventual divergência é efetuada através da aplicação de um filtro no tempo; sendo A uma variável genérica, com nível de tempo $\mathrm{n}$, o filtro possui parâmetro $\alpha$ e produz a variável filtrada $A_{f}$ através da seguinte expressão:

$A_{f}=A^{n}+\alpha\left(A^{n+1}-2 A^{n}+A^{n-1}\right) / 2$

Para a região costeira modelada, foi adotada uma grade regular cartesiana, com 120 elementos na direção EW e 80 na direção NS, e com espaçamento horizontal de cerca de $1 \mathrm{~km}$; na vertical, foram considerados 11 níveis sigma (Tab. 1). Essa grade possui 9600 células, das quais 5527 são marítimas. $\mathrm{O}$ modelo foi integrado com passos de tempo de $15 \mathrm{~s}$ (para o modo externo) e $300 \mathrm{~s}$ (para os internos). Os parâmetros friccionais utilizados nas simulações são os mesmos de Oey et al. (1985a), em seu estudo de alta resolução do estuário de Hudson - Raritan (EUA); os valores numéricos utilizados foram portanto: constante $C$, na expressão de $A_{M}$, igual a 0.01 ; comprimento de rugosidade $\mathrm{z}_{0}=0.2 \mathrm{~cm}$; e valor do parâmetro $\alpha$, nas filtragens temporais acima citadas, igual a 0.1 .

O modelo foi utilizado exclusivamente em simulações de maré, para componentes isoladas e para a maré astronômica completa, a partir da especificação das correspondentes oscilações nos contornos; estas foram calculadas com base nas constantes harmônicas extraídas dos mapas cotidais 
fornecidos pelo modelo de plataforma de Harari \& Camargo (1994). O limite externo deste modelo de plataforma é indicado na Figura la, juntamente com as posições de medições pelágicas de maré consideradas em seu contorno (na Plataforma do Rio de Janeiro - PRJ, a $100 \mathrm{~m}$; na Plataforma de Santos PSN, a $92 \mathrm{~m}$; e na Plataforma do Paraná - PPR, a 74 $\mathrm{m})$. Entretanto, as informações fornecidas pelo modelo de plataforma não foram diretamente usadas neste trabalho; na realidade, os valores iniciais de amplitude e de fase das componentes nos contornos da grade da área costeira de Santos foram corrigidos, considerando amplificações e defasagens suplementares, através da comparação de resultados preliminares do modelo com as análises de registros anuais do Porto de Santos, efetuadas por Harari \& Camargo (1995); nessa comparação, foram tomadas as médias de 46 análises anuais de maré. Essas correções suplementares são necessárias em virtúde de incertezas nos valores do contorno adotados no modelo de plataforma, os quais foram baseados em registros pelágicos relativamente curtos, entre 14 e 31 dias, com interpolações entre os pontos de medição.

Tabela 1. Níveis verticais sigma considerados nos processamentos do POM.

\begin{tabular}{|c|c|}
\hline NIVEL & $\begin{array}{c}\text { COORDENADA } \\
\text { SIGMA }\end{array}$ \\
\hline & 0.000 \\
\hline 01 & -0.03125 \\
\hline 02 & -0.0625 \\
\hline 03 & -0.125 \\
\hline 04 & -0.250 \\
\hline 05 & -0.500 \\
\hline 06 & -0.750 \\
\hline 07 & -0.875 \\
\hline 08 & -0.9375 \\
\hline 09 & -0.96875 \\
\hline 10 & -1.000 \\
\hline 11 & \\
\hline
\end{tabular}

A imposição de condições de contorno no modelo requereu a especificação das variações do nivel do mar nas bordas e também nos pontos internos imediatamente vizinhos; nesse caso, as correntes calculadas pelo modelo nas primeiras linhas e colunas internas da grade foram também adotadas para os contornos externos abertos (O'Connor, 1991).

A especificação das elevações de maré $\eta$ no tempo t, a partir de constantes harmônicas de

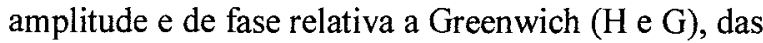
frequências angulares das oscilações de maré $\omega$, das fases astronômicas iniciais $v_{0}$ e das correções nodais de amplitude e fase $\left(\mathrm{f}_{\mathrm{n}}\right.$ e $\left.\mathrm{u}_{\mathrm{n}}\right)$, para a somatória $(\Sigma)$ das componentes de maré, é realizada com a expressão:

$\eta=\sum f_{n} H \cos \left(\omega t+v_{0}+u_{n}-G\right)$
Em todos os processamentos efetuados, os campos de temperatura e de salinidade foram mantidos uniformes $\mathrm{e}$ as forçantes meteorológicas foram anuladas. Condições iniciais de repouso foram adotadas em todas as simulações realizadas.

Deve-se notar que, embora os processamentos realizados tenham considerado apenas forçantes de maré, foi utilizada a formulação completa das equações do POM, com todos os termos presentes nas equações; a exclusão dos efeitos meteorológicos e de densidade foi obtida apenas com a anulação dos campos de vento e de pressão atmosférica na superfície e com a adoção de campos de temperatura e de salinidade uniformes e invariantes no tempo (de modo a evitar qualquer gradiente de densidade na área). Dessa forma, foram levados em conta praticamente todos os efeitos que podem influenciar as marés, tais como a difusão horizontal e vertical; no entanto, efeitos de magnitude menor, resultantes da interação entre as marés e as circulações geradas por efeitos meteorológicos e de densidade, não foram incluídos nos resultados obtidos.

A utilização do POM em simulações de maré para áreas costeiras pode ser encontrada nos trabalhos de Oey et al. (1985), Galperin \& Mellor (1990), O'Connor (1991) e Stacey et al. (1995).

Numa etapa inicial, o modelo foi processado considerando isoladamente a componente lunar principal (M2) e a componente solar principal (S2), cada qual por um período de 5 dias. A seguir, um processamento final com todas as principais componentes de maré foi efetuado, para um período de 31 dias, o que permitiu analisar o comportamento global das marés na área costeira e, principalmente, evidenciar os contrastes entre a sizígia e a quadratura; nesse processamento, foram consideradas conjuntamente as componentes $\mathrm{Q} 1, \mathrm{O} 1, \mathrm{P} 1, \mathrm{~K} 1, \mathrm{~N} 2$, $\mathrm{M} 2, \mathrm{~S} 2, \mathrm{~K} 2$ e M3, as quais são responsáveis por mais de $90 \%$ da energia de maré na área modelada (Harari \& Camargo, 1995; Mesquita \& Harari, 1983).

Nos dois primeiros processamentos efetuados, por se tratar de componentes isoladas, não houve a necessidade de referência a período específico, de modo que foram adotadas correções nodais de amplitude unitárias e de fase nulas (com fases astronômicas iniciais também nulas); já no terceiro processamento, com as nove principais componentes de maré conjuntamente, há a necessidade de escolha de período definido de simulação, para a especificação exata da fase astronômica inicial e das correções nodais das componentes; dessa forma, os 31 dias de processamento tem início em 00 GMT de 28 de Dezembro de 1979 e final em 00 GMT de 28 de Janeiro de 1980; como o primeiro resultado do modelo é referente à primeira hora de processamento, foram obtidos 744 resultados horários; no entanto, considerando a necessidade de equilíbrio 
hidrodinâmico, em função da adoção de condições iniciais de repouso, foram analisados somente os resultados a partir do segundo dia de processamento, desde 00 GMT de 30 de dezembro de 1979; o período analisado se extende até $23 \mathrm{~h}$ GMT de 27 de Janeiro de 1980 , o que corresponde a 29 dias completos, com 696 valores horários (desde o instante $\mathrm{t}=48 \mathrm{~h}$ até $\mathrm{o}$ instante $\mathrm{t}=743 \mathrm{~h}$ de processamento).

As séries temporais de elevação e de correntes de superficie de todos os pontos da grade, resultantes do processamento com a maré astronômica completa, foram submetidas a análises de maré pelo Método Harmônico (Franco, 1988; Franco \& Harari, 1987). Estas análises forneceram as constantes harmônicas de amplitude e fase das componentes de maré e de correntes de maré, as quais foram utilizadas na elaboração dos mapas cotidais de elevação e dos mapas de eixos das elipses das correntes.

\section{Resultados}

Os resultados obtidos nos processamentos do modelo foram analisados através de: mapas de elevação, correntes na superficie e correntes médias na vertical (cobrindo toda a grade); séries temporais de elevações e correntes de superfície (em pontos de interesse selecionados); e perfis verticais de correntes horizontais (para instantes de interesse, nos pontos selecionados). Os mapas são divididos em duas partes: a primeira contém resultados para a área completa modelada, mas em geral excluindo as regiões interiores rasas; e a segunda apresenta um detalhamento dessas regiões interiores, onde se tem o Canal de São Vicente, o Canal do Porto de Santos e o Canal de Bertioga (bem como a área costeira adjacente); esta divisão é necessária tendo em vista as diferenças nos regimes hidrodinâmicos entre a área costeira mais profunda e as regiões interiores rasas, especialmente em relação à intensidade das correntes. Deve-se também observar que, devido ao grande número de vetores (ou eixos de elipses) nos mapas da região completa, foi plotado um resultado a cada seis; no entanto, para as regiões interiores rasas, foram plotados os vetores de correntes (ou eixos de elipses) de todos os pontos marítimos.

Em todas as simulações, ao partir de uma condição de repouso, o equilíbrio hidrodinâmico entre as bordas e o interior da grade foi atingido ao final de aproximadamente 1 dia de integração do modelo.

Os processamentos referentes à $\mathrm{M} 2$ e à $\mathrm{S} 2$ possibilitaram a obtenção dos mapas com a evolução horária das correntes e elevações de superficie no decorrer dos respectivos ciclos.

Com os resultados do processamento envolvendo as nove principais componentes de maré conjuntamente, foram traçados os mapas de correntes e elevações da superfície, bem como de correntes médias na vertical, nas marés enchentes e vazantes máximas e nas preamares e baixamares, para as condições de sizígia e de quadratura; como exemplo, a Figura 2 ilustra correntes de superficie vazantes máximas na sizígia, nas regiões interiores rasas. Adicionalmente, foram analisadas séries temporais de elevação e de correntes de superfície, em pontos de grade selecionados, e perfis verticais das correntes, para instantes e pontos de grade de interesse.

A Figura 3 fornece perfis verticais das correntes vazantes máximas na sizígia, em vários pontos da grade. A Figura 4 apresenta os valores máximos e mínimos atingidos pela maré astronômica completa, na integração do modelo por um período de 29 dias; na apresentação desses valores extremos, as Figuras são restritas às regiões interiores rasas, as quais apresentam feições e variabilidades de maior interesse.

As análises de maré das séries temporais de elevação e de correntes de superfície possibilitaram a composição dos respectivos mapas cotidais e de eixos das elipses, sendo os mais significativos apresentados nas Figuras 5 a 7 ; esses mapas são referentes às componentes $\mathrm{M} 2$ e $\mathrm{S} 2$, que possuem as maiores amplitudes de maré na área de estudo.

$\mathrm{Na}$ Figura 8 se encontram séries temporais referentes ao marégrafo de Torre Grande, no Porto de Santos, com comparações entre resultados do modelo, observações e previsões harmônicas da maré. Nesta figura podem ser identificados os períodos de sizígia e quadratura, bem como os instantes de enchentes, vazantes, preamares e baixamares.

\section{Discussão}

O comportamento das marés numa área costeira é muito influenciado pelas marés ao largo; além disso, em pequena escala, gradientes do potencial de maré são desprezíveis; consequentemente, em geral, nos modelos costeiros, as forçantes de maré são definidas exclusivamente pelas oscilações de maré nos contornos abertos. No entanto, há certas variações na forma de especificação dessas oscilações na borda; alguns modelos consideram valores de nível do mar e de correntes, enquanto outros adotam a especificação desses valores somente nas condições enchentes (e adotam condições radiacionais para as vazantes). Uma solução particularmente útil foi adotada no presente modelo, onde se tem a especificação das variações do nível do mar nas bordas e também nos pontos internos imediatamente vizinhos; nesse caso, as correntes calculadas pelo modelo nas primeiras linhas e colunas internas da grade são também válidas para as bordas abertas (O'Connor, 1991). Neste contexto, para as análises hidrodinâmicas a serem apresentadas 
a seguir, deverão ser considerados os resultados de Harari \& Camargo (1994), cujos mapas cotidais da plataforma sudeste brasileira foram utilizados para a implementação das condições de contorno deste modelo costeiro.

Os resultados dos processamentos iniciais, referentes à propagação das componentes M2 e S2 isoladamente, demonstram que as correntes vazantes máximas dessas ondas de maré, na região costeira, são nas direções leste - sudeste, enquanto que as respectivas enchentes tem correntes para oeste noroeste; nessas simulações se tem um enorme contraste entre a região costeira mais profunda e as áreas interiores rasas; por exemplo, nos instantes de máximas enchentes e vazantes, as correntes da M2 na superfície, na região costeira, não chegam a atingir 10 $\mathrm{cm} / \mathrm{s}$, enquanto que, nas áreas interiores, ultrapassam $40 \mathrm{~cm} / \mathrm{s}$; o mesmo ocorre para as correntes de superfície da S2, onde se tem valores máximos de 5 e de $30 \mathrm{~cm} / \mathrm{s}$, respectivamente. Quanto às preamares (e baixamares) subsequentes, essas duas componentes principais da maré também apresentam características similares: os valores máximos (e mínimos) atingidos se encontram na parte oeste da área costeira e também em direção às regiões internas rasas; na região dos canais, a preamar da M2 tem valores entre 30 e 42 $\mathrm{cm}$, enquanto que na $\mathrm{S} 2$ as máximas se encontram entre 18 e $27 \mathrm{~cm}$. Mapas horários das correntes de superficie dessas duas componentes principais demonstram que as correntes de maré na região costeira apresentam rotação anti-horária. Outro aspecto de interesse se encontra nas correntes enchentes (e vazantes) dos canais: tanto no Canal de Bertioga como no Canal de São Vicente, se tem a convergência (e divergência) de correntes em sentidos opostos; entretanto, no Canal do Porto de Santos, as enchentes (e vazantes) da M2 e da S2 se processam com correntes num único sentido. Também é interessante notar as diferenças de intensidade das correntes nas extremidades da Baía de Santos, na direção do mar aberto, onde se tem fortes correntes na área contígua ao Porto de Santos e correntes muito fracas no lado do Canal de São Vicente.

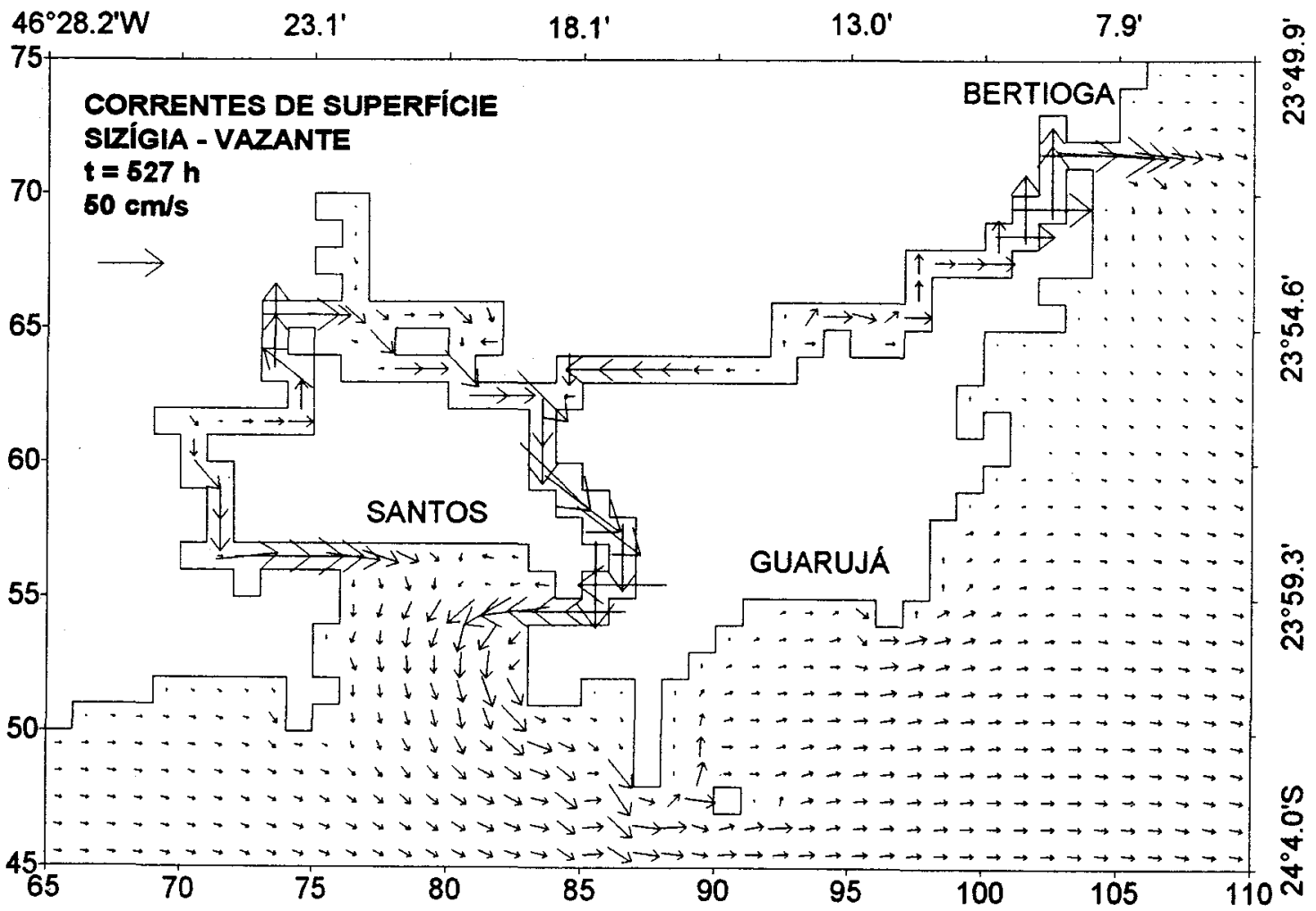

Fig. 2. Correntes de superficie vazantes máximas na sizígia $(t=527 \mathrm{~h})$, nas áreas interiores rasas. 

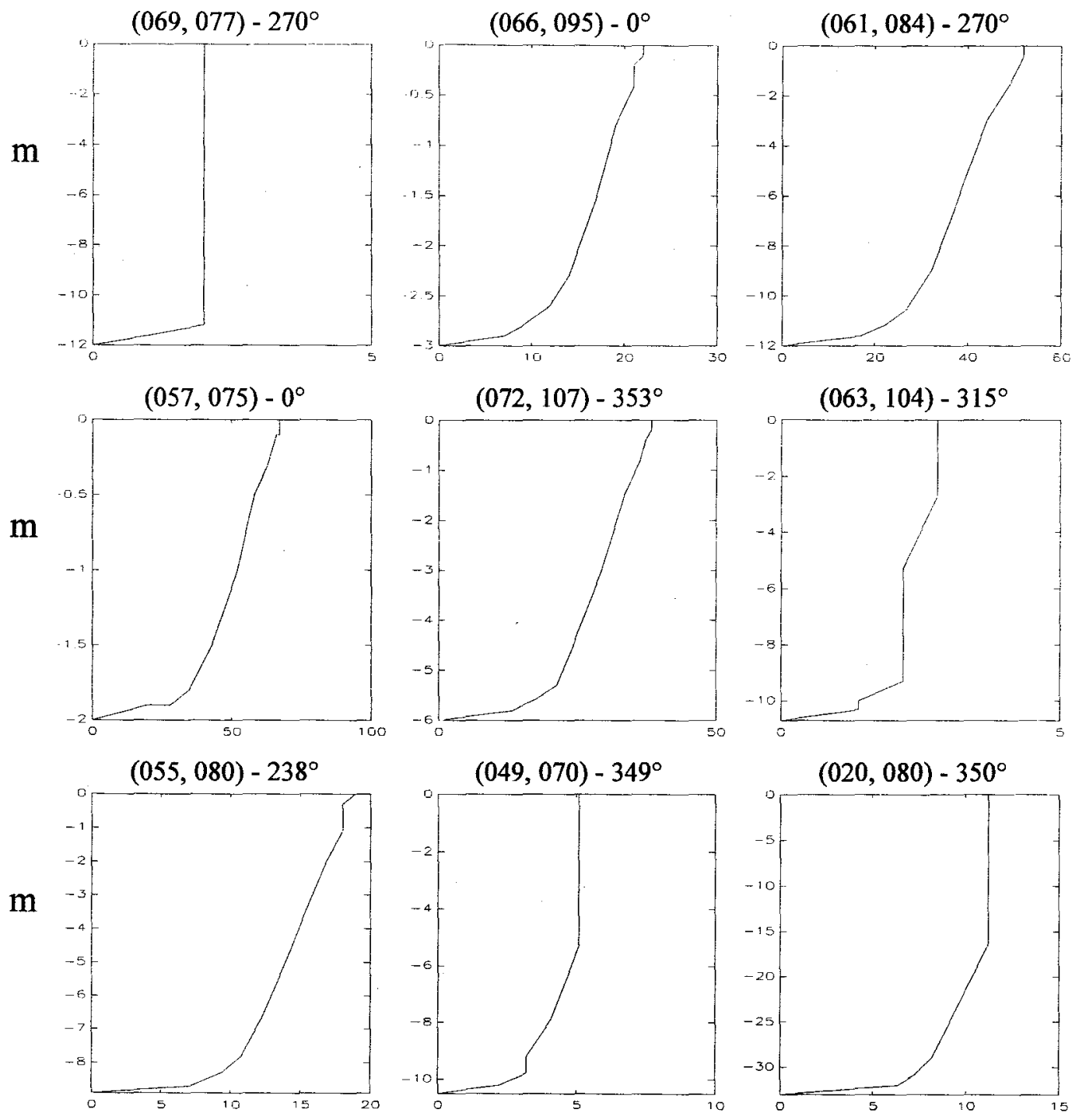

Perfis verticais de correntes na vazante da sizigia (linha , coluna) dos pontos na grade - direção da corrente Direção relativa ao eixo $\mathrm{EW}$

Eixo vertical: profundidade (m)

Eixo horizontal: intensidade da corrente $(\mathrm{cm} / \mathrm{s})$

Fig. 3. Perfis verticais de correntes nas vazantes máximas de sizígia, em diversos pontos da grade.

$\mathrm{Na}$ simulação referente à composição das 9 componentes principais de maré, em condições de sizígia, as correntes de superfície vazantes mais intensas apresentaram valores de $20.2 \mathrm{~cm} / \mathrm{s}$ na área costeira e de $74.3 \mathrm{~cm} / \mathrm{s}$ na regiões rasas (Fig. 2); esses valores, referentes ao instante $t=527 \mathrm{~h}$, são mais intensos que os de enchente, especialmente o relativo às áreas rasas; as baixamares subsequentes (em $\mathrm{t}=$ $529 \mathrm{~h}$ ) atingiram elevações mínimas de $-82 \mathrm{~cm}$ (na parte profunda) e de $-93 \mathrm{~cm}$ (na parte rasa); esses valores são também de módulo maior que os de preamares. Na Baía de Santos, nota-se grande contraste de intensidade das correntes entre o lado de São Vicente e o lado de Santos / Guarujá; nas enchentes (e vazantes) de sizígia, se tem convergência (e divergência) das correntes nos Canais de Bertioga e
São Vicente e correntes num único sentido no Canal do Porto de Santos (Fig. 2). Na sizígia, em virtude da preponderância da $\mathrm{M} 2$ e da S2 na circulação de maré da área, as correntes apresentam rotação anti-horária ao longo do ciclo de maré.

Em condições de quadratura, as correntes máximas (de vazante) na superficie possuem limites bem menores do que na sizígia: $8.1 \mathrm{~cm} / \mathrm{s}$ na área costeira mais profunda e $26.0 \mathrm{~cm} / \mathrm{s}$ na mais rasa (em t $=661 \mathrm{~h}$ ); as baixamares subsequentes são as que apresentam os menores valores de queda do nível do mar, com $-11.2 \mathrm{~cm}$ (no instante $\mathrm{t}=664 \mathrm{~h}$ ). Durante a quadratura, as correntes de superfície não apresentam um sentido definido de rotação; e nas vazantes das áreas rasas, as correntes nos Canais de Bertioga, São Vicente e Santos são num único sentido. 
a

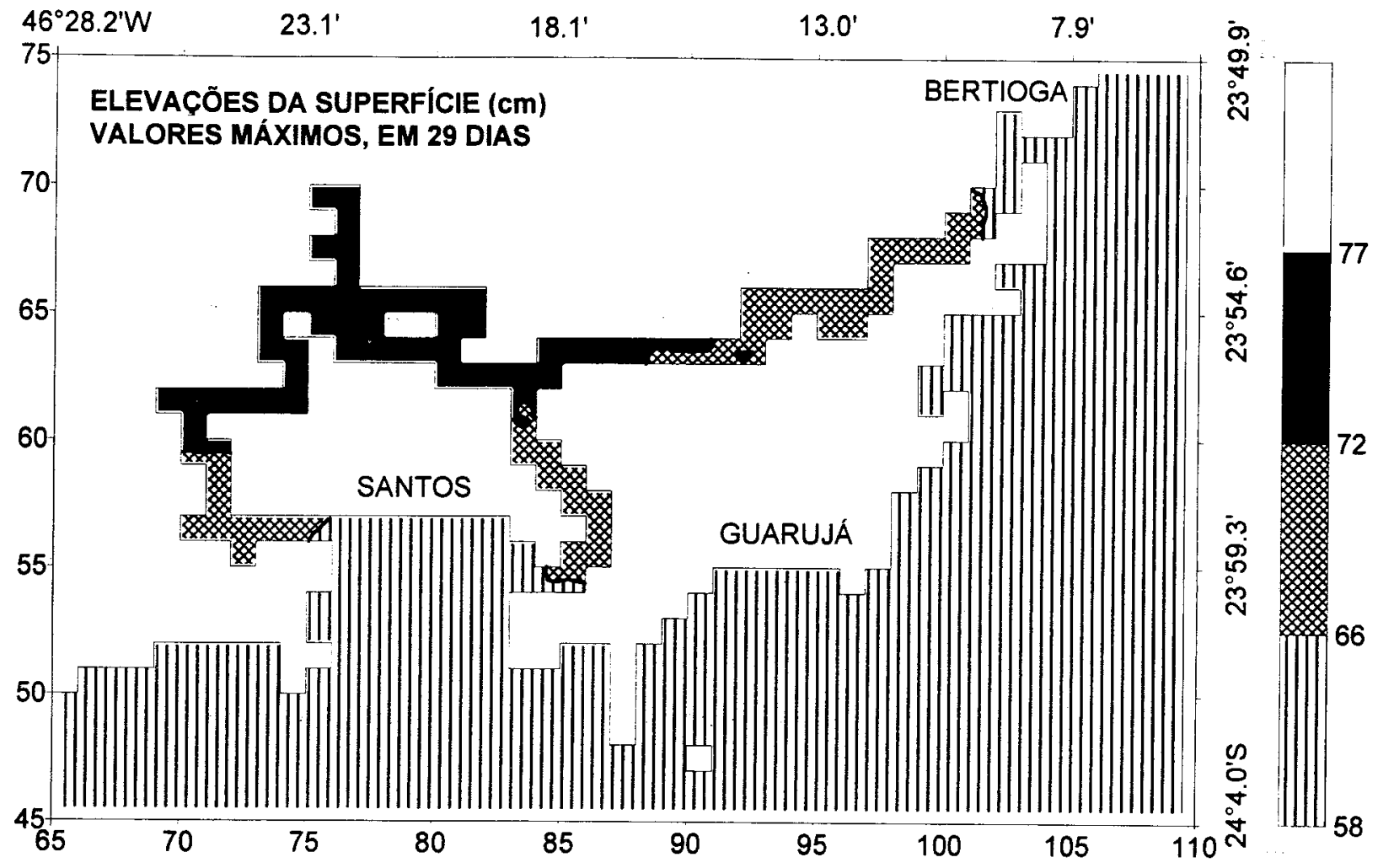

b

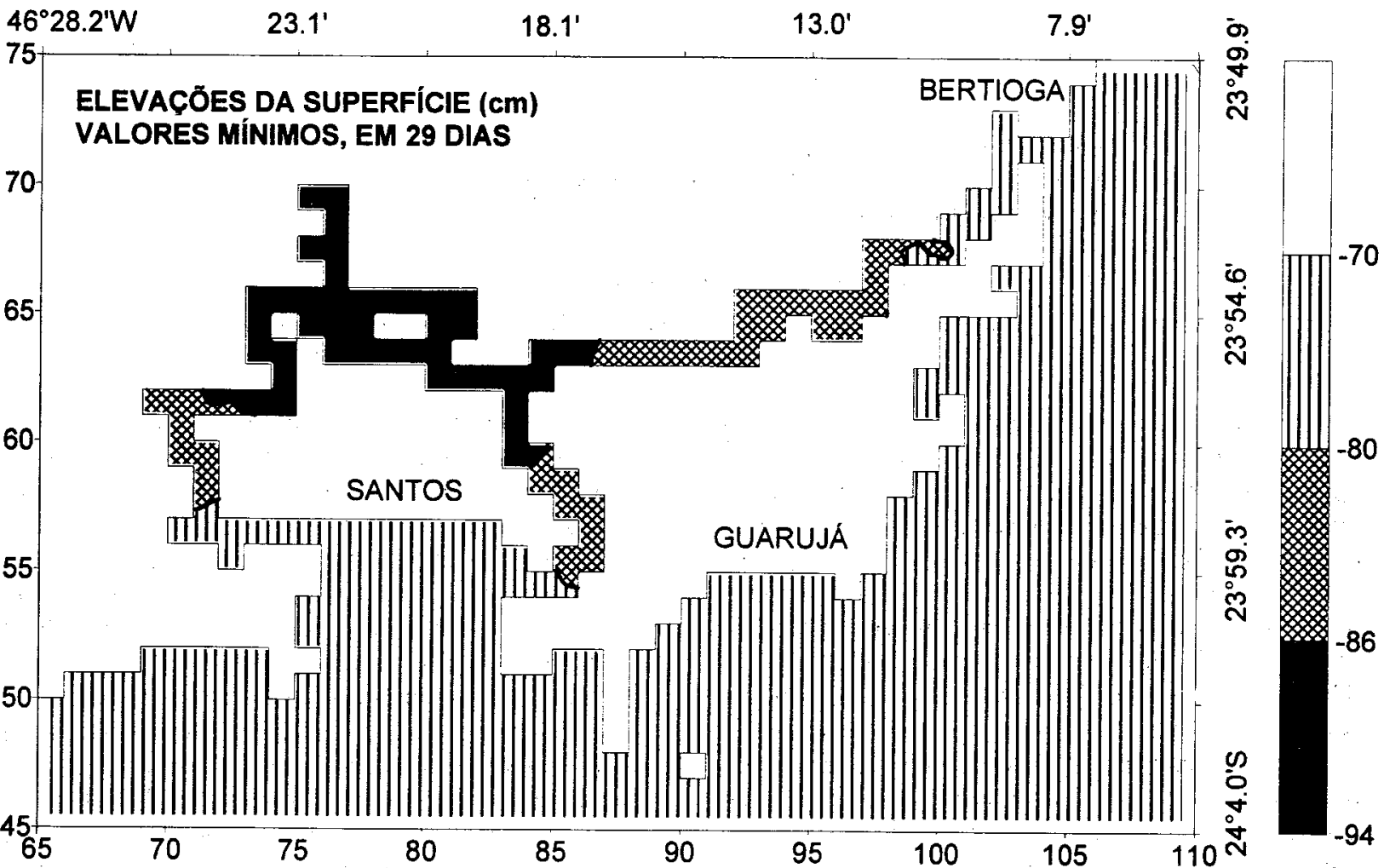

Fig. 4. Valores de elevação de maré máximos (a) e mínimos (b), na integração do modelo por um período de 29 dias, nas áreas interiores rasas. 
a

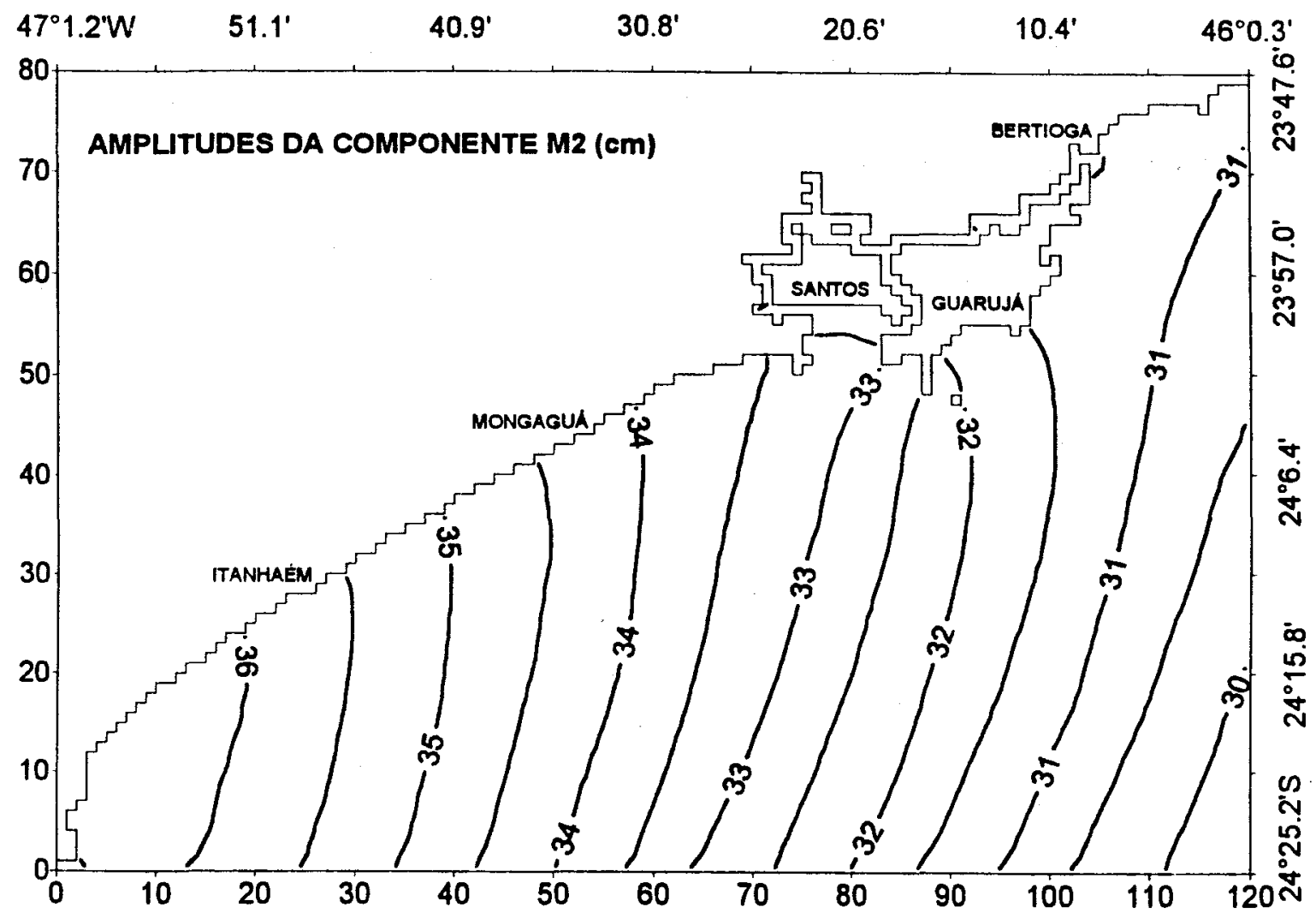

b

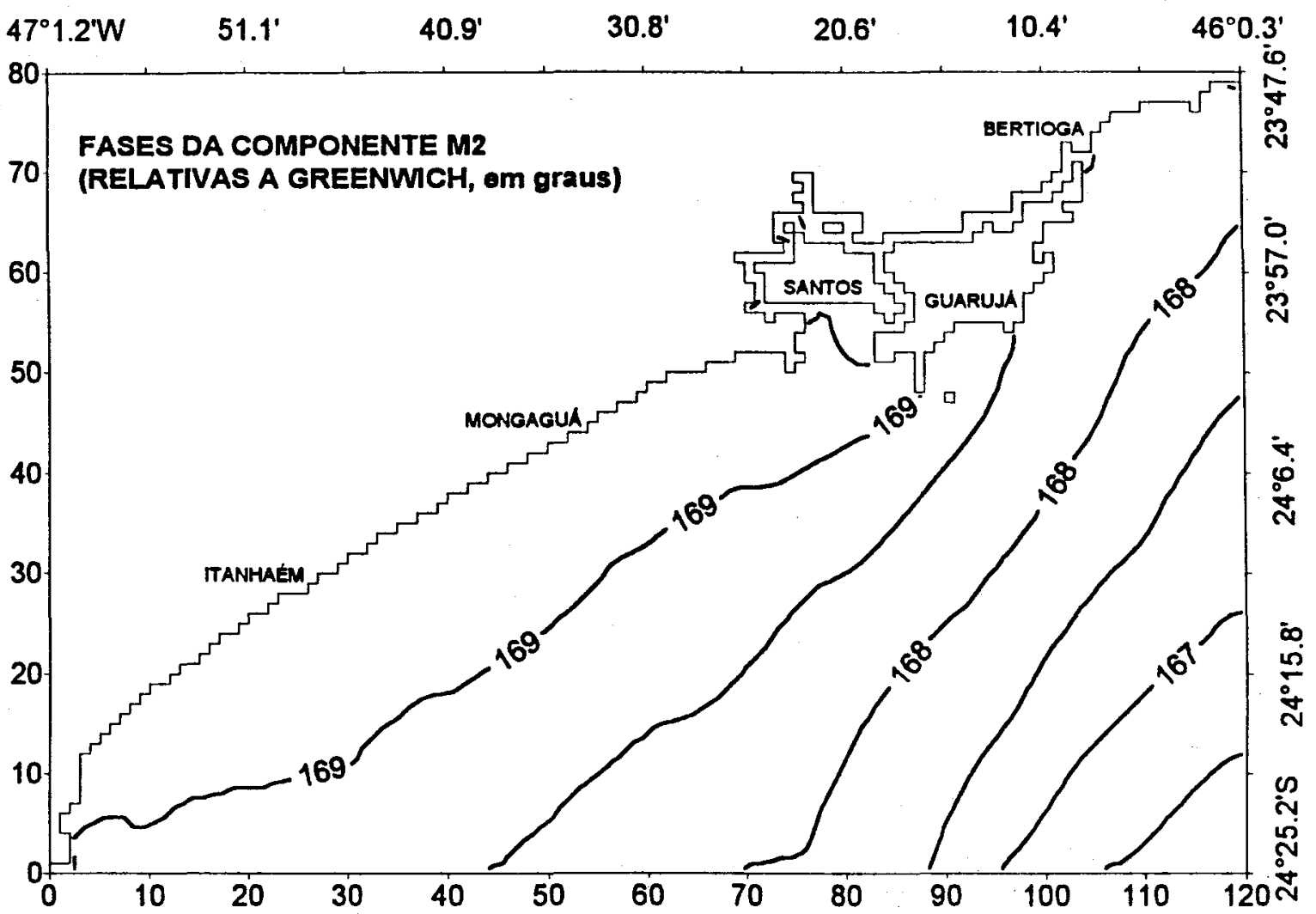

Fig. 5. Amplitudes e fases relativas a Greenwich das componentes de maré M2 (a, b) e S2 (c, d), para a área completa. 
c

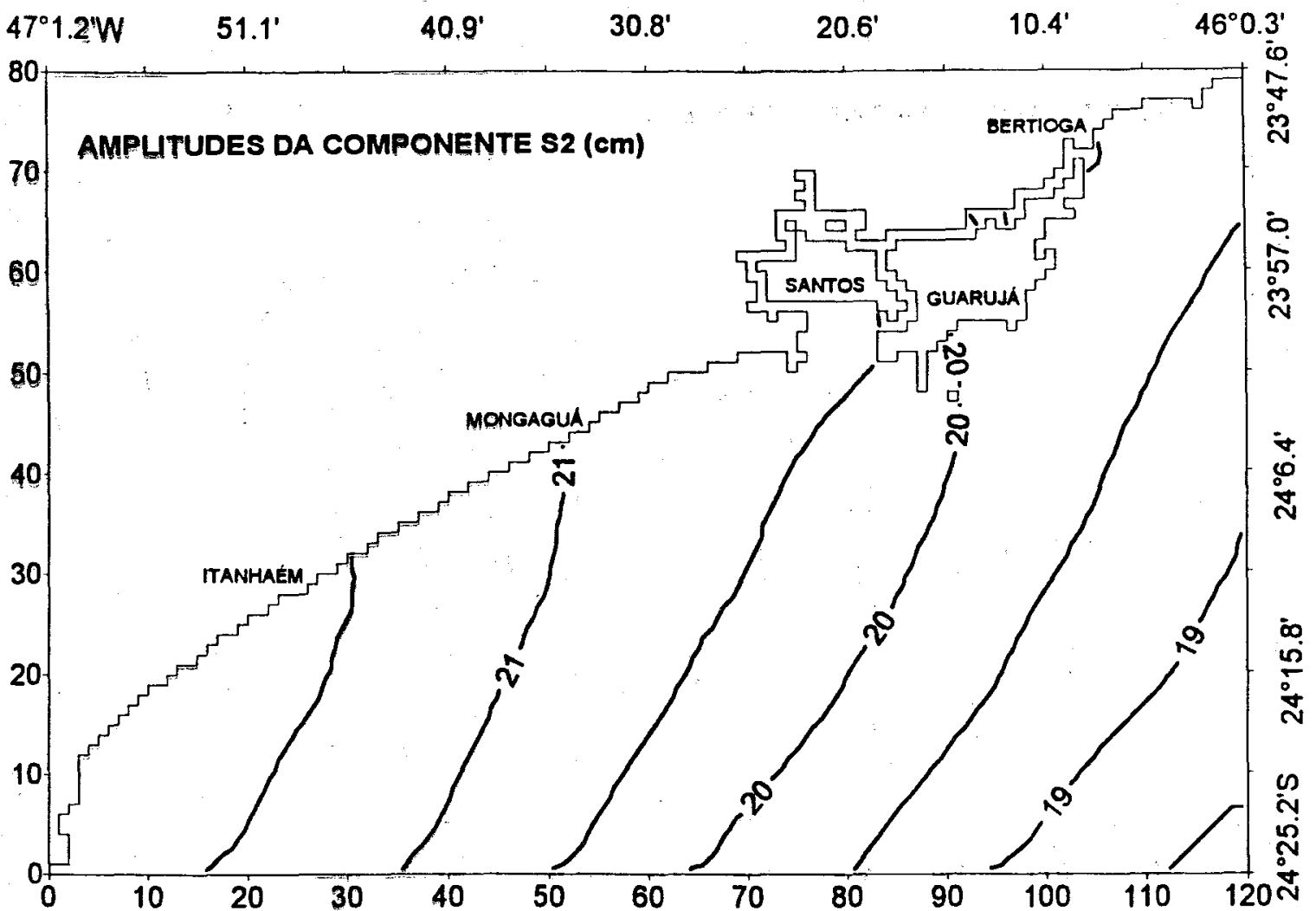

d

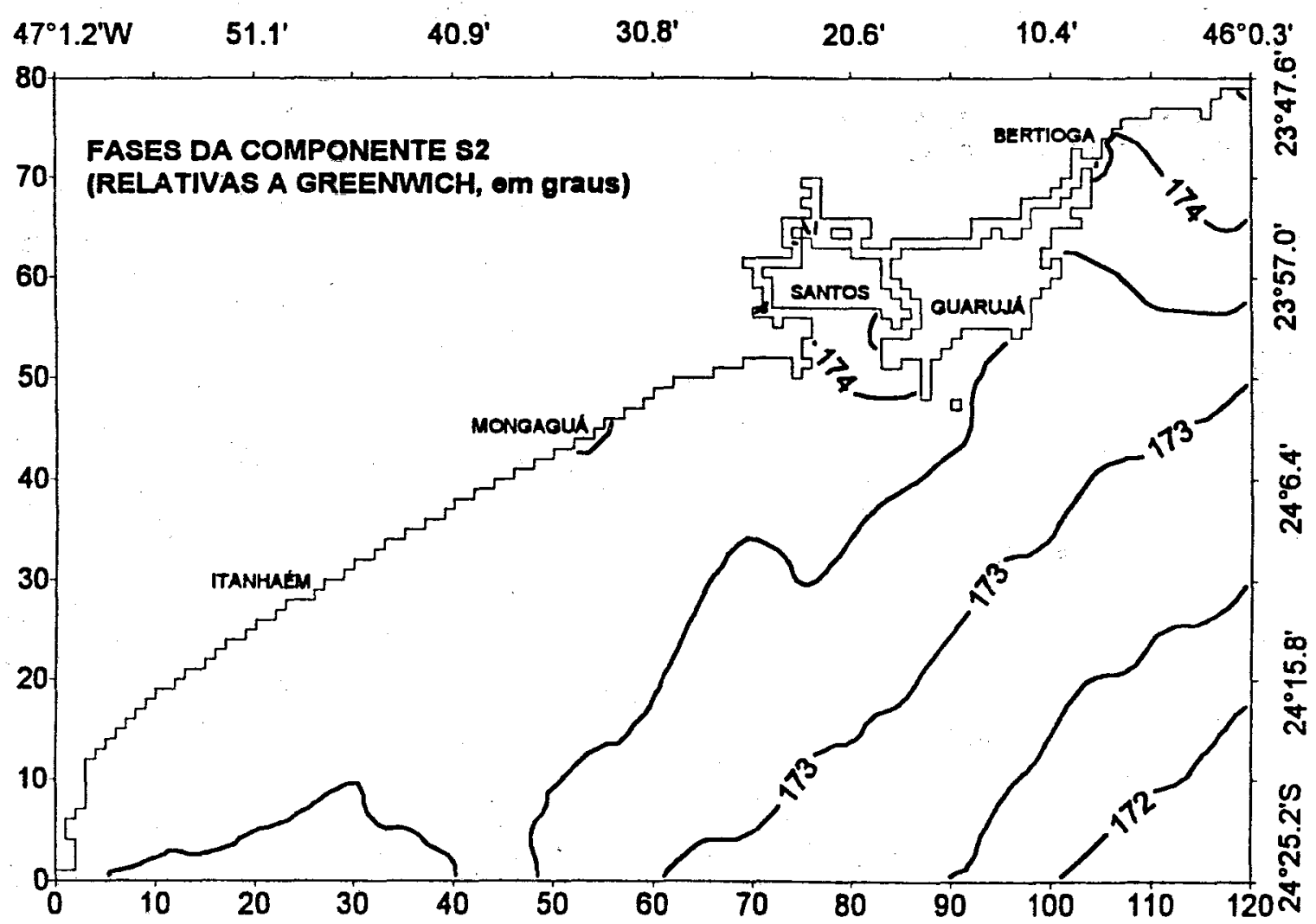

Fig. 5. Cont. 
Deve-se notar que os valores máximos de elevações e correntes na sizígia e na quadratura, acima mencionados, são referentes aos instantes específicos de cálculo, no período de simulação considerado; obviamente, em cada ciclo de quadratura - sizígia há variações nas intensidades das respectivas circulações; além disso, foram considerados instantes aproximados médios para a área, quanto à ocorrência dos eventos enchente preamar - vazante - baixamar; evidentemente, há atrasos significativos entre sub-áreas específicas; por exemplo, enquanto se tem uma baixamar na área costeira, as áreas rasas ainda apresentam o final da vazante. Por outro lado, as feições gerais descritas, como as diferenças de intensidade de circulação entre a parte costeira mais profunda e as regiões interiores rasas, os contrastes na circulação da Baía de Santos e as condições de convergência / divergência nos Canais de Bertioga e São Vicente, são comuns a todos os ciclos de maré na região modelada.

Nas séries temporais de elevações e correntes de superficie, o contraste nos valores calculados é entre a região mais profunda, com pequena amplitude de maré e correntes fracas, e a região mais rasa, com grande amplitude de variação do nível do mar e intensas correntes associadas. A intensificação das correntes nas áreas rasas é devida, basicamente, à conservação da massa. Além dessa característica, outro efeito notório se encontra no fato que, em geral, correntes de vazante são bem mais intensas que as de enchente; isto se deve à influência da friç̧ão do fundo, que é muito mais efetiva na enchente (onde a coluna d'água tem menor espessura).

Os perfis verticais das correntes horizontais (Fig. 3) demonstram o caráter barotrópico das marés, com valores aproximadamente uniformes ao longo da vertical, excetuando-se as camadas mais próximas ao fundo, onde $o$ atrito reduz significativamente a intensidade das correntes (deve-se também considerar que o modelo adota um perfil logaritmico para as correntes na camada limite, com velocidades nulas no fundo). Novamente, agora ao longo das colunas, se tem correntes bem mais intensas nas áreas rasas, por efeito de continuidade. Como exemplos numéricos, o ponto oceânico de lin, col $(20,80)$ tem correntes com intensidade em torno de $10 \mathrm{~cm} / \mathrm{s}$, enquanto que no Canal do Porto de Santos e na entrada do Canal de São Vicente, nos pontos de lin, col $(61,84)$ e $(57,75)$, os valores de correntes chegam a ultrapassar $50 \mathrm{~cm} / \mathrm{s}$. Por outro lado, é necessário ressaltar que a uniformidade dos perfis também se deve à adoção de uma densidade uniforme na área modelada; a inclusão da estratificação no modelo possibilitará estudos sobre interações entre as marés e os campos de temperatura e salinidade, as quais geram cisalhamentos significativos, com circulações em duas camadas, principalmente em áreas rasas. De qualquer forma, os perfis verticais de correntes obtidos são importantes, particularmente na estimativa do transporte de sedimentos junto à camada do fundo, especialmente no Canal do Porto de Santos, onde são realizadas dragagens periódicas, com a finalidade de manter as condições de segurança de navegação.

A assimetria entre máximos e mínimos da maré num período de 29 dias é facilmente notada, especialmente nas áreas internas rasas (Fig. 4). Os extremos de maré mais significativos calculados pelo modelo foram de +69 e $-82 \mathrm{~cm}$, na parte Sudoeste da região modelada, e +76 e $-92 \mathrm{~cm}$, nas regiões interiores rasas (Fig. 4). Essas assimetrias são relacionadas ao efeito conjugado da conservação de massa (que intensifica as correntes nas regiões mais rasas) com a fricção no fundo (que é mais efetiva em colunas d'água menores).

As amplitudes e fases das principais componentes de maré apresentam distribuições espaciais cujas características são descritas a seguir. Todas as componentes apresentam aumentos de amplitude na parte Oeste / Sudoeste da região modelada e em direção às áreas mais interiores dos canais. As diurnas e a ter-diurna possuem sentido de propagação nitidamente de Sul para Norte, enquanto que as semi-diurnas se propagam de Sudeste para Noroeste. Foram selecionados para apresentação, neste trabalho, os mapas cotidais das duas mais importantes componentes de maré na área de estudo, M2 e S2 (Figs 5 e 6).

De fato, a componente M2 é a de maior amplitude na área modelada, com valores variando de 30 a $36 \mathrm{~cm}$ na área mais profunda, num forte gradiente para oeste, e de 31 a $38.5 \mathrm{~cm}$ nas áreas interiores rasas (Figs 5a e 6a); a S2 é a segunda maior componente de maré da região, com amplitudes aumentando de 18 a $22 \mathrm{~cm}$, de leste para oeste, e uma amplificação de 19 a $24 \mathrm{~cm}$ nos canais (Figs $5 \mathrm{c}$ e $6 \mathrm{c}$ ). $\hat{E}$ interessante notar que a componente de maré M3 apresenta uma taxa de amplificação extremamente grande, em torno de $100 \%$, tanto no sentido leste oeste como em direção às áreas internas rasas.

A configuração das isolinhas de mesma fase demonstra o sentido de propagação das ondas de maré na área costeira, cujas características definem as áreas rasas mais favoráveis a amplificações; outro aspecto de interesse nessas isolinhas é a indicação dos encontros das ondas de maré, nos Canais de Bertioga e de São Vicente, a partir das composição de ondas provenientes de suas extremidades (Fig. 6).

As elipses das correntes de superfície das componentes de maré são representadas através de seus eixos maior e menor. Em geral, nas partes rasas do modelo se tem uma intensificação das correntes de maré e um alinhamento das mesmas com o contorno terrestre. Um aspecto de grande interesse se encontra na intensificação das correntes em parte da Baía de Santos, no lado que se extende desde o Canal do Porto até a Ilha da Moela, margeando o continente; 
esta feição é observada em todas as componentes de correntes de maré. Nos mapas dos eixos das elipses ressalta-se a grande intensidade das correntes associadas às componentes M2 e S2 (Fig. 7); para essas componentes, o sentido predominante do eixo maior, na parte mais profunda, é de noroeste sudeste; nas áreas rasas, as máximas intensidades de correntes calculadas para a M2 e a S2 foram de 48 $\mathrm{cm} / \mathrm{s}$ e de $30 \mathrm{~cm} / \mathrm{s}$, respectivamente; um aspecto de interesse nos cálculos do modelo se encontra nas intensas correntes da $\mathrm{M} 3$, num padrão praticamente unidirecional.

Foi observada uma boa concordância entre as características das ondas de maré M2 e S2 determinadas pelos processamentos do modelo com estas ondas isoladamente e pela simulação delas em conjunto com as demais ondas de maré (cujos resultados na forma de séries temporais foram submetidos a análises de maré pelo método harmônico, para a separação dos efeitos das componentes). Porém, é interessante notar que as assimetrias entre enchentes e vazantes são maiores ao considerar o conjunto das componentes, o que indica a relação entre as assimetrias e efeitos não lineares (entre as componentes de maré).

Os resultados obtidos com os processamentos do POM foram comparados com análises harmônicas de registros de maré disponiveis. A comparação de maior interesse se encontra na Tabela 2, referente ao marégrafo de Torre Grande, no Porto de Santos, cujos dados no período de 1944 a 1989 foram analisados por Harari \& Camargo (1995). A boa concordância verificada entre os valores de amplitude e de fase calculados pelo modelo e por análise harmônica também se justifica pelas correções introduzidas nas condições de contorno do modelo, após a realização de diversos processamentos preliminares, como anteriormente citado.

$\mathrm{Na}$ Figura 8 se encontram as séries temporais de maré no ponto correpondente a Torre Grande, considerando observações (após subtração da média), previsão harmônica com 44 componentes (constantes da análise de 1980) e, finalmente, resultados do modelo; nesta Figura, não foi incluída a curva de previsão harmônica com 09 componentes (e constantes médias de 46 análises anuais), por ser praticamente coincidente com a dos resultados do modelo; é interessante notar a concordância entre os resultados obtidos com o modelo e a previsão harmônica com 44 componentes, a qual inclui várias componentes de pequeno fundo; por outro lado, os resultados do modelo diferem de observações somente quando da ocorrência de significativas variações do nível médio do mar, devidas a efeitos meteorológicos intensos; esses efeitos foram particularmente importantes nos intervalos $t^{*}=48 \mathrm{~h} \mathrm{a}$ $96 \mathrm{~h}$ (sobreelevação), $\mathrm{t}^{*}=192 \mathrm{~h}$ a $240 \mathrm{~h}$ (rebaixamento) e $\mathrm{t}^{*}=624 \mathrm{~h}$ a $670 \mathrm{~h}$ (nova sobreelevação); $t^{*}$ é igual a $t-48 \mathrm{~h}$, isto é, a origem do tempo na Fig. 8 é fixada desconsiderando o período inicial de obtenção de equilíbrio hidrodinâmico pelo modelo; afora os intervalos de tempo citados, ou seja, na ausência de eventos meteorológicos significativos, o modelo reproduz satisfatoriamente as marés observadas. Os desvios padrão das observações e previsões em relação aos resultados do modelo, para essas séries com 696 valores horários, foram de $25.6 \mathrm{~cm}$ no caso das observações de maré, $5.4 \mathrm{~cm}$ na previsão harmônica com 44 componentes e $1.3 \mathrm{~cm}$ na previsão harmônica com 09 componentes. Em princípio, com a inclusão no modelo de efeitos meteorológicos e de variações de densidade da água do mar, será possível reproduzir de forma mais precisa ainda as oscilações da superficie observadas, inclusive na ocorrência de eventos meteorológicos significativos.

Considerando os trabalhos científicos com medições de correntes na área, só foi possível comparar resultados de correntes do modelo com observações esparsas; de fato, a obtenção de séries temporais de correntes com equipamentos fundeados apresenta enormes dificuldades, tendo em vista o grande trânsito de embarcações na região, além do transporte de sedimentos e da atividade biológica, os quais causam perdas e danos em instrumentos. De qualquer forma, é interessante comparar os resultados obtidos na Baía de Santos e na entrada do Canal do Porto com as medições realizadas pela FUNDESPA (1996), ao menos em termos de valores máximos; a média dos valores máximos observados na Baía de Santos foi de $24.6 \mathrm{~cm} / \mathrm{s}$, enquanto que, no ponto linha, coluna $=055,080$ do modelo, o máximo calculado foi de $20.6 \mathrm{~cm} / \mathrm{s}$; na entrada do Canal do Porto de Santos, a média das correntes máximas observadas foi de $55.9 \mathrm{~cm} / \mathrm{s}$, enquanto que com o modelo foi calculado um máximo de $51.0 \mathrm{~cm} / \mathrm{s}$, na Ponta dos Práticos, no ponto linha, coluna $=057,087$. Resultados do modelo do Canal do Porto de Santos de Yassuda (1991) indicam, para as condições de quadratura, em Torre Grande, correntes vazantes máximas de $20 \mathrm{~cm} / \mathrm{s}$; no modelo atual, este ponto corresponde ao de linha, coluna $=061,084$, onde foram calculadas correntes vazantes máximas na quadratura, entre os instantes $\mathrm{t}=651 \mathrm{~h}$ e $\mathrm{t}=686 \mathrm{~h}$, de $21 \mathrm{~cm} / \mathrm{s}$.

O trabalho aqui apresentado indicou feições de marés que são concordantes com outros trabalhos de áreas costeiras próximas e da plataforma; excetuando os que foram utilizados para especificar as condições de contorno do presente modelo, podese comparar os resultados obtidos para a região de Santos com as análises de maré de Cananéia e Ubatuba, apresentadas em Mesquita \& Harari (1983), cujos valores de amplitude e fase das componentes são similares. Embora Cananéia e Ubatuba não se encontrem no interior da região modelada, ou mesmo muito próximo a ela, na realidade, a área de Santos se localiza "a meio caminho" entre Ubatuba e Cananéia; 
a

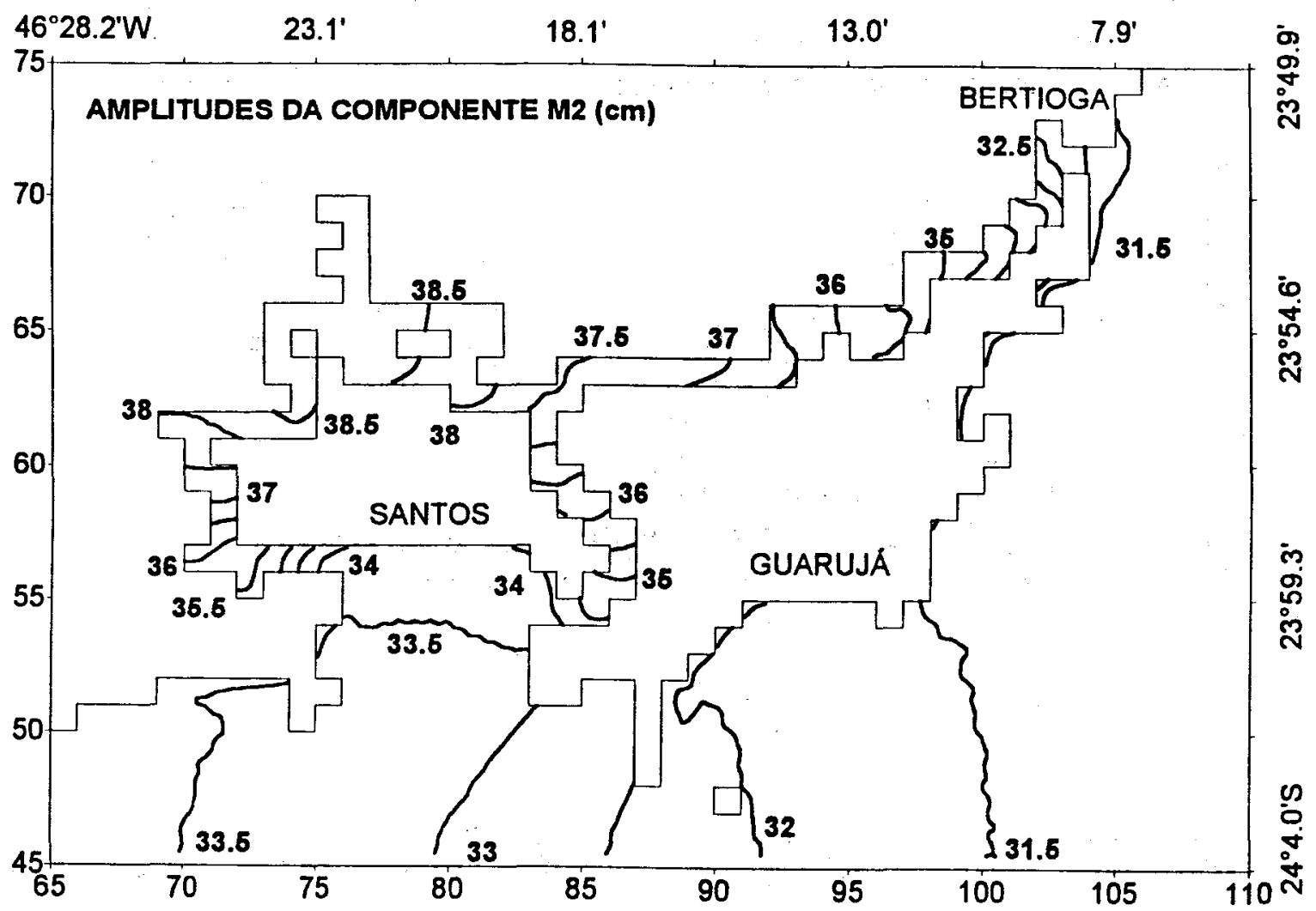

b

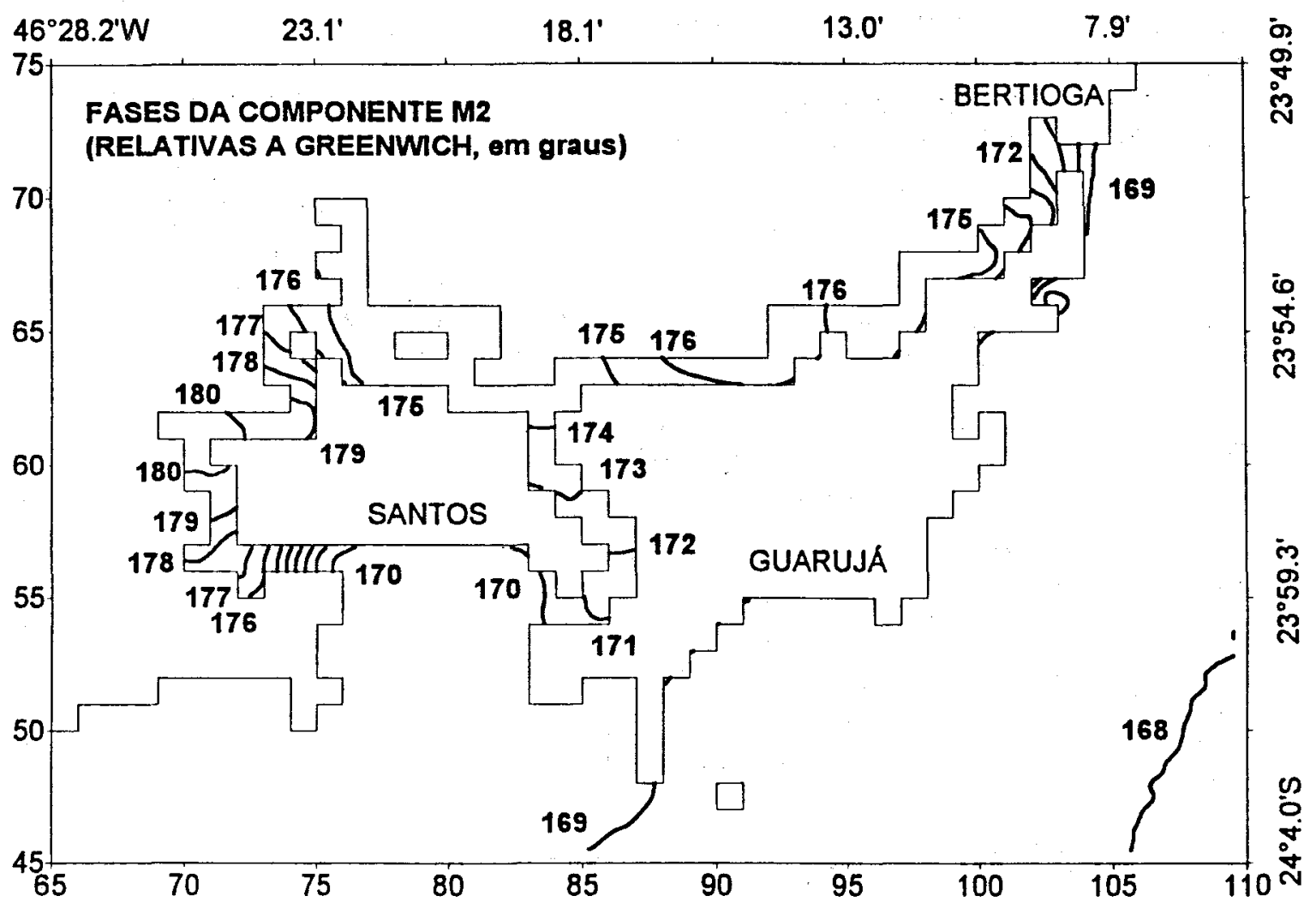

Fig. 6. Amplitudes e fases relativas a Greenwich das componentes de maré M2 (a, b) e S2 (c, d), para as regiões interiores rasas. 
c

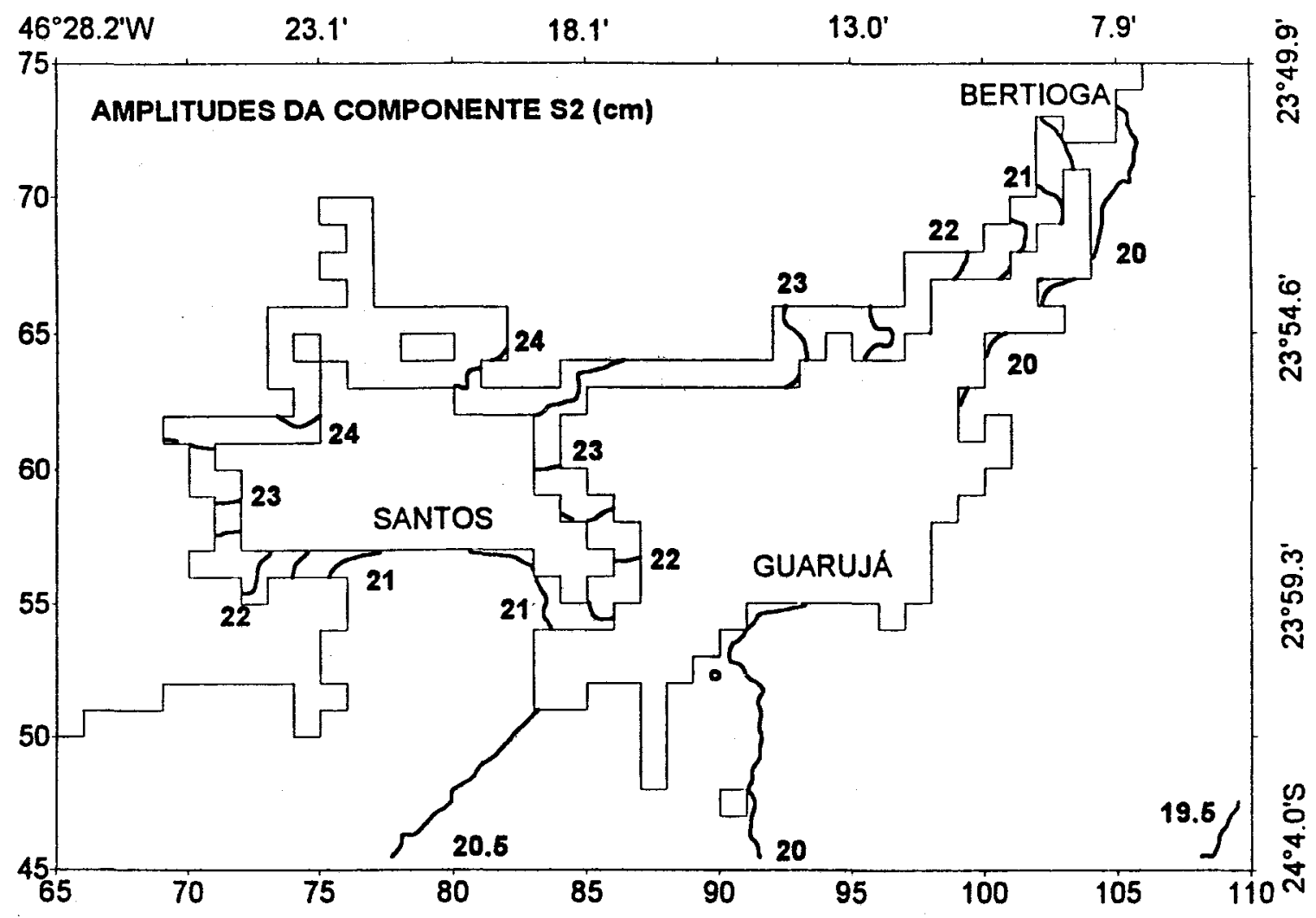

d

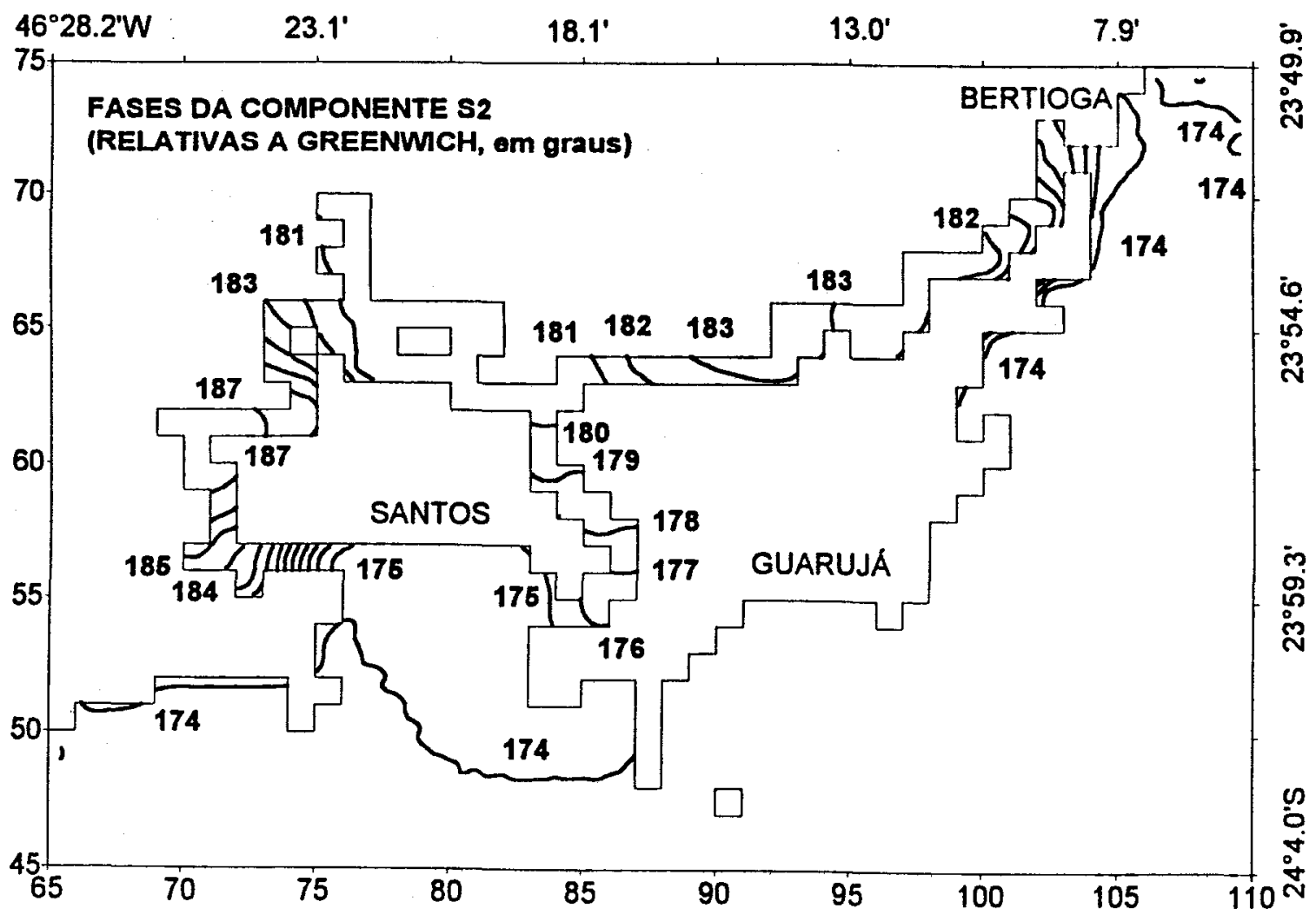

Fig. 6. Cont. 
a

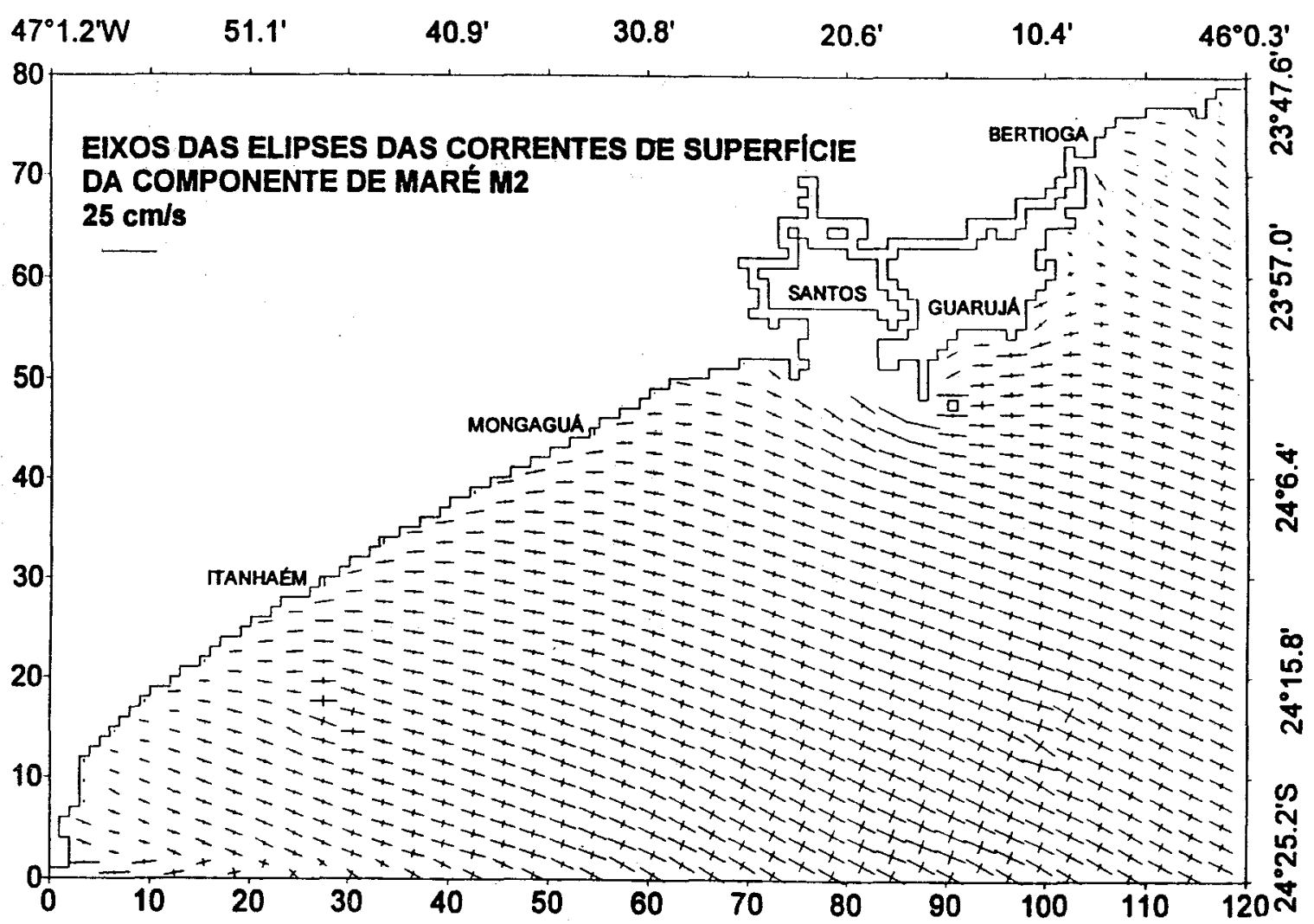

b

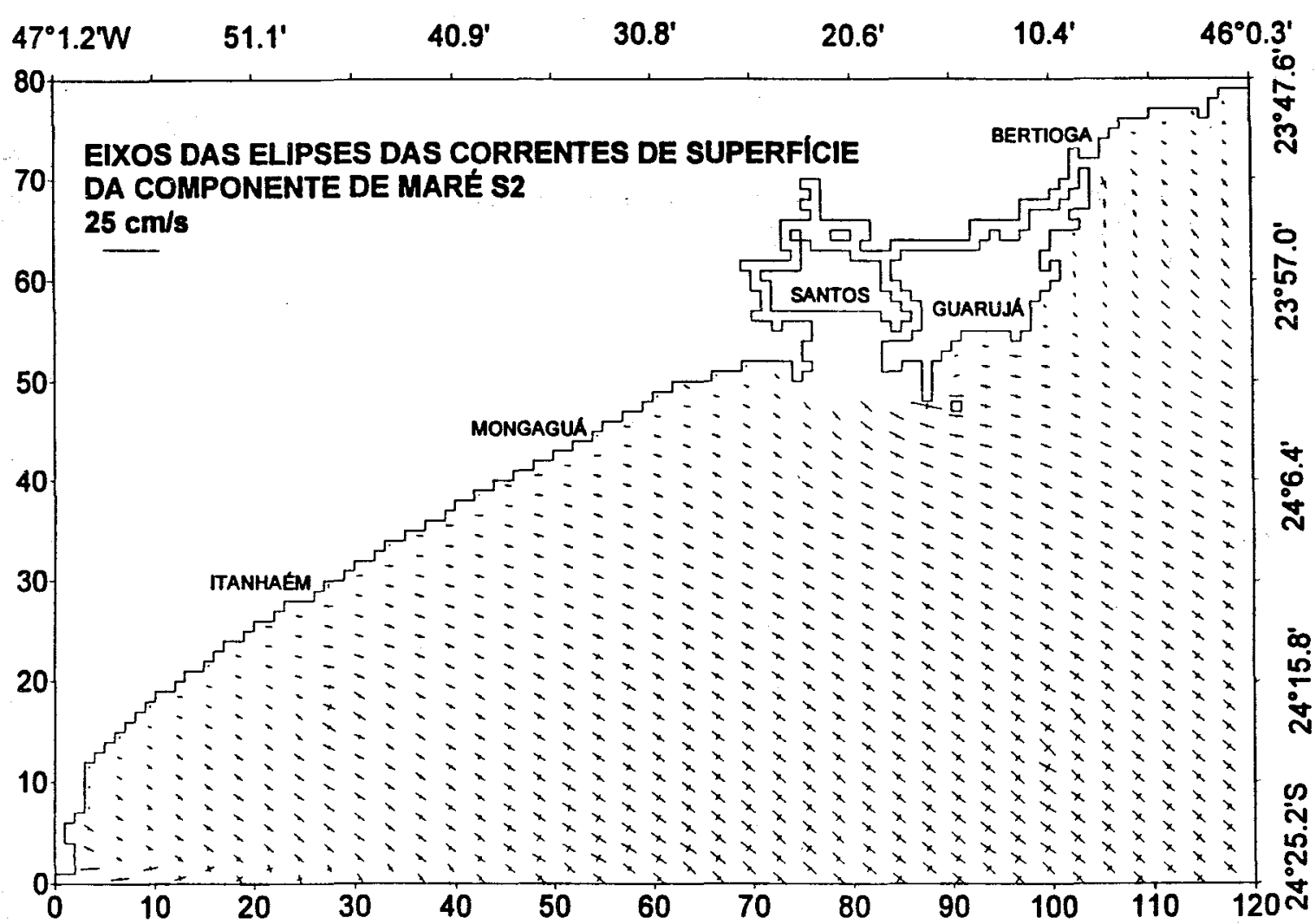

Fig. 7. Eixos das elipses das correntes de superfície das componentes de maré M2 (a, c) e S2 (b, d), para a área completa (a, b) e para as regiões interiores rasas $(c, d)$. 
c

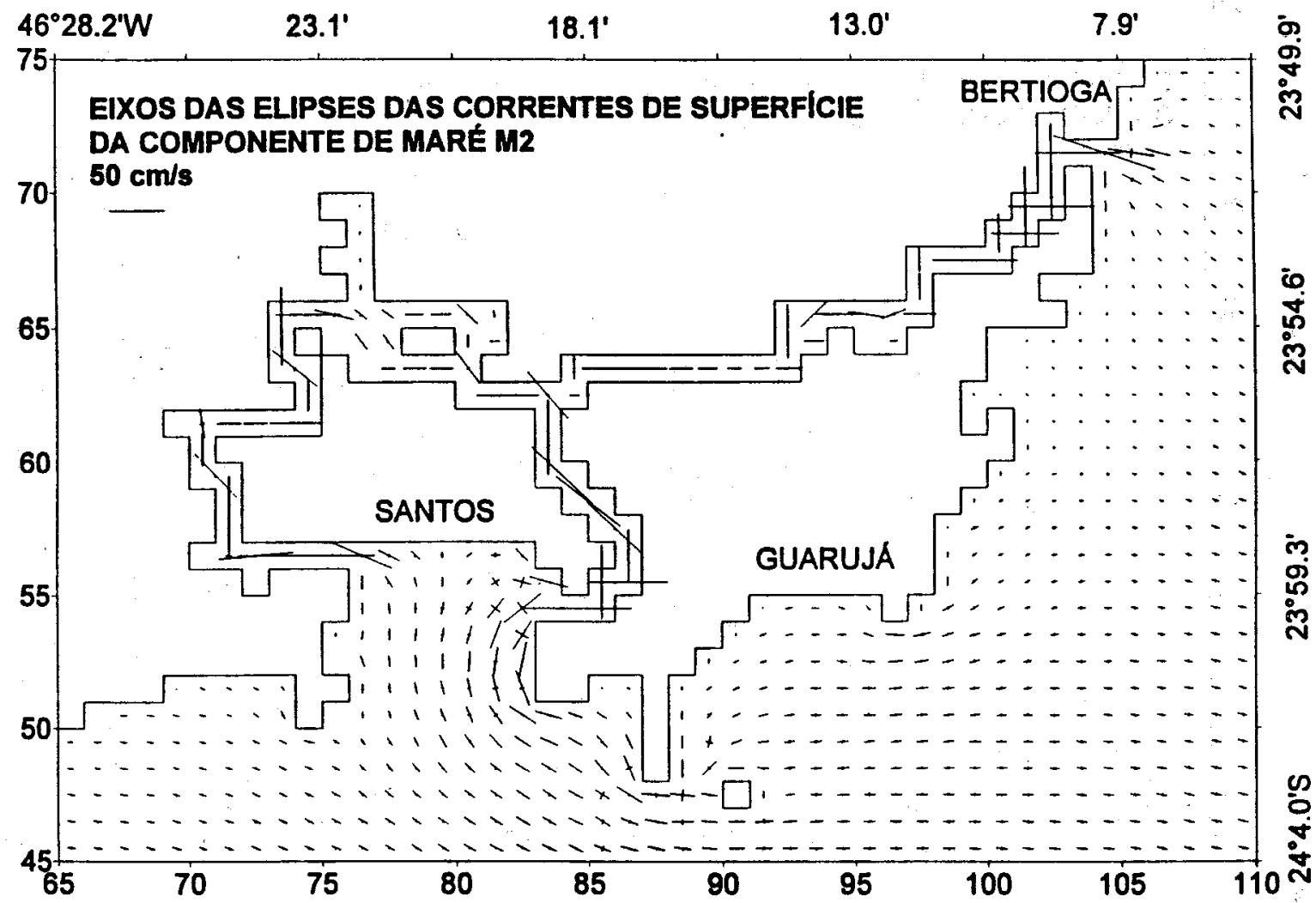

d

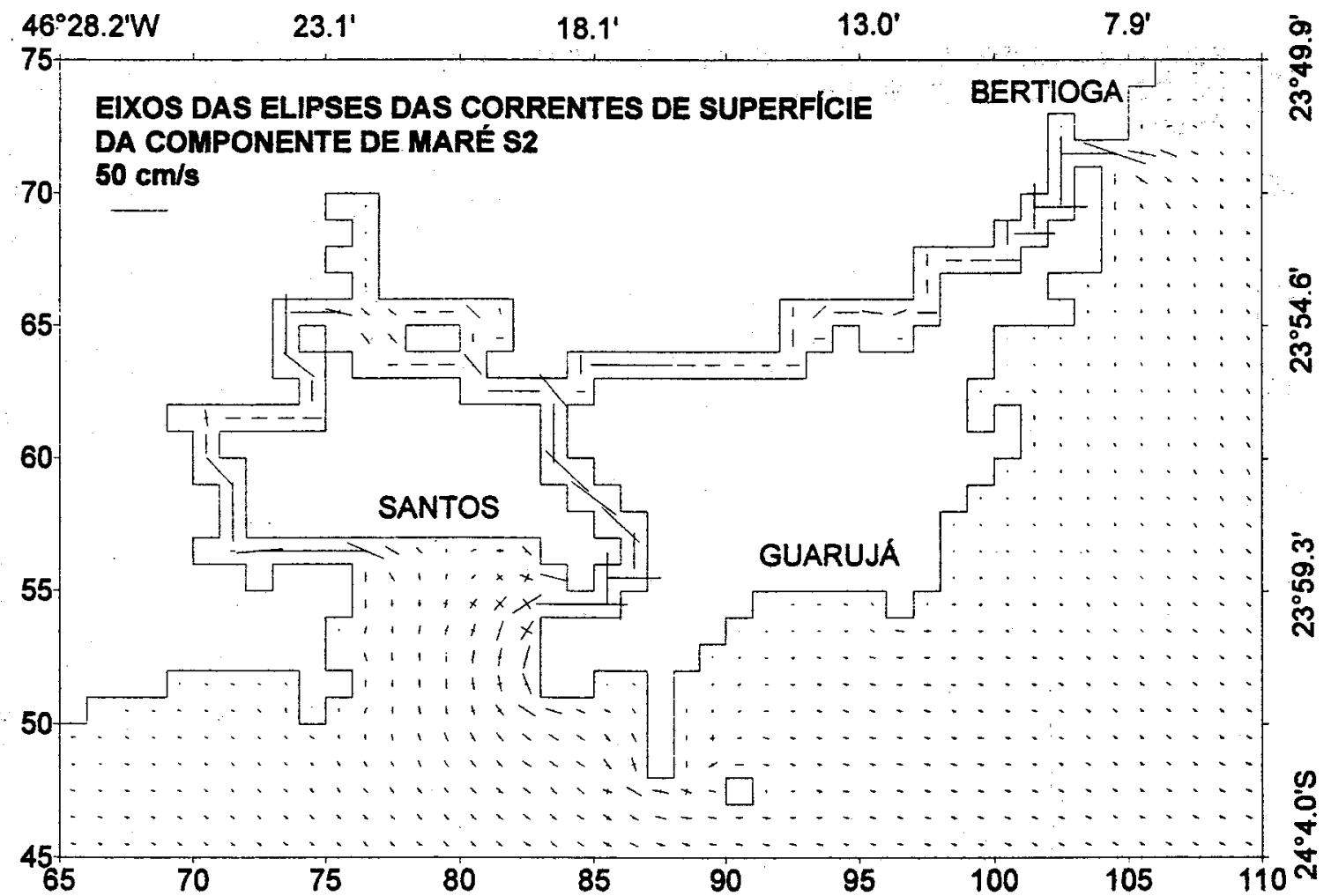

Fig. 7. Cont. 
considerando portanto as posições geográficas, e sendo as ondas de maré na plataforma muito longas, a comparação é válida. É interessante notar que, apesar de amplificações e atrasos de maré locais, por estarem os marégrafos de Ubatuba, Santos e Cananéia em áreas interiores e abrigadas, os valores numéricos das constantes harmônicas de Santos se encontram, em geral, entre os correspondentes valores numéricos de Ubatuba (mais ao Norte) e de Cananéia (mais ao Sul). Por outro lado, ao incluir no modelo forçantes meteorológicas e variações do campo de massa, os correspondentes resultados, especialmente os referentes aos campos de temperatura e salinidade, poderão ser comparados a resultados de diversos outros trabalhos científicos, como o de Mesquita (1974).

Em resumo, o trabalho desenvolvido permitiu determinar as principais características das marés na região modelada, tais como: o grande contraste de elevações e correntes entre a região costeira mais profunda e as áreas interiores rasas, o qual ocorre em praticamente todas as simulações realizadas; as condições de convergência e de divergência das correntes nos Canais de Bertioga e de São Vicente, que foram observadas em todos os casos estudados, com exceção das condições de quadratura (Fig. 2); as intensidades maiores das vazantes se comparadas às enchentes, especialmente na maré astronômica completa, mas não no caso de simulações com componentes isoladas; o padrão uniforme das correntes de maré segundo a vertical, com exceção das camadas próximas ao fundo, onde o atrito atenua bastante as intensidades (Fig. 3); assimetrias entre enchentes e vazantes são pequenas ao considerar componentes de maré isoladamente, mas são importantes na composição das principais ondas de maré, o que gera diferenças significativas entre os máximos e mínimos de maré na região (Fig. 4); os mapas cotidais das principais componentes de maré indicam suas amplificações, atrasos de fase e sentidos predominantes de propagação (Figs 5 e 6 ); os eixos das elipses de correntes de maré novamente mostram as intensificações nas áreas rasas (Fig. 7); se observa um caráter progressivo das ondas de maré na parte profunda, cuja propagação em canais com duas extremidades produz áreas de encontro de marés, especialmente no interior dos Canais de São Vicente e Bertioga; finalmente, a concordância dos resultados do modelo com previsões harmônicas da maré foi demonstrada (Fig. 8).

Em termos regionais, os aspectos de maior interesse no estudo realizado são: o grande contraste das intensidades das circulações de maré, na parte mais profunda e nas regiões internas rasas; as marcantes diferenças de intensidade de correntes nos dois lados da Baía de Santos; a convergência e divergência das correntes enchentes e vazantes dos Canais de São Vicente e de Bertioga, onde ocorrem encontros das ondas de maré provenientes de suas extremidades; as significativas assimetrias de maré nas áreas rasas; e a rotação anti-horária das correntes de maré na região costeira.

O modelo implementado pode ser utilizado em previsões operacionais das marés e das correntes de maré na área estudada, de grande utilidade para estudos ambientais, a navegação costeira e a segurança de operação do Porto de Santos.

As próximas etapas do desenvolvimento de modelos nesta região compreendem: o aumento da resolução nas áreas internas rasas, através de um aninhamento de grades, com a adoção de um espaçamento final de $200 \mathrm{~m}$; a inclusão de efeitos meteorológicos e de variações do campo de densidade, em condições estacionárias e transientes (em adição às marés); e, finalmente, a consideração de áreas de alagamento e de exposição do fundo, através de grades variáveis no tempo.

Tabela 2. Constantes harmônicas de amplitude e fase (relativas a Greenwich), para resultados do modelo (linha, coluna = 061, 084) e análises harmônicas de observações (em Torre Grande, no Porto de Santos).

\begin{tabular}{|c|c|c|c|c|}
\hline $\begin{array}{c}\text { COMP. DE } \\
\text { MARÉ }\end{array}$ & $\begin{array}{c}\text { AMPLITUDES - } \\
\text { ANÁLISES } \\
(\mathrm{cm})\end{array}$ & $\begin{array}{c}\text { AMPLITUDES- } \\
\text { MODELO } \\
(\mathrm{cm})\end{array}$ & $\begin{array}{c}\text { FASES - } \\
\text { ANÁLISES } \\
(\mathrm{gaus})\end{array}$ & $\begin{array}{c}\text { FASES - } \\
\text { MODELO } \\
\text { (graus) }\end{array}$ \\
\hline $\mathrm{Q} 1$ & 3.0 & 3.04 & 99.4 & 98.52 \\
\hline $\mathrm{O} 1$ & 11.5 & 11.49 & 125.4 & 125.80 \\
\hline $\mathrm{P} 1$ & 2.3 & 2.32 & 182.7 & 183.41 \\
\hline $\mathrm{K} 1$ & 6.4 & 6.35 & 187.7 & 188.36 \\
\hline N2 & 5.1 & 5.11 & 235.2 & 235.42 \\
\hline M2 & 36.7 & 36.90 & 173.4 & 173.56 \\
\hline S2 & 23.1 & 23.10 & 179.0 & 179.42 \\
\hline K2 & 7.5 & 7.51 & 168.8 & 169.21 \\
\hline M3 & 5.6 & 5.53 & 358.7 & 359.66 \\
\hline
\end{tabular}



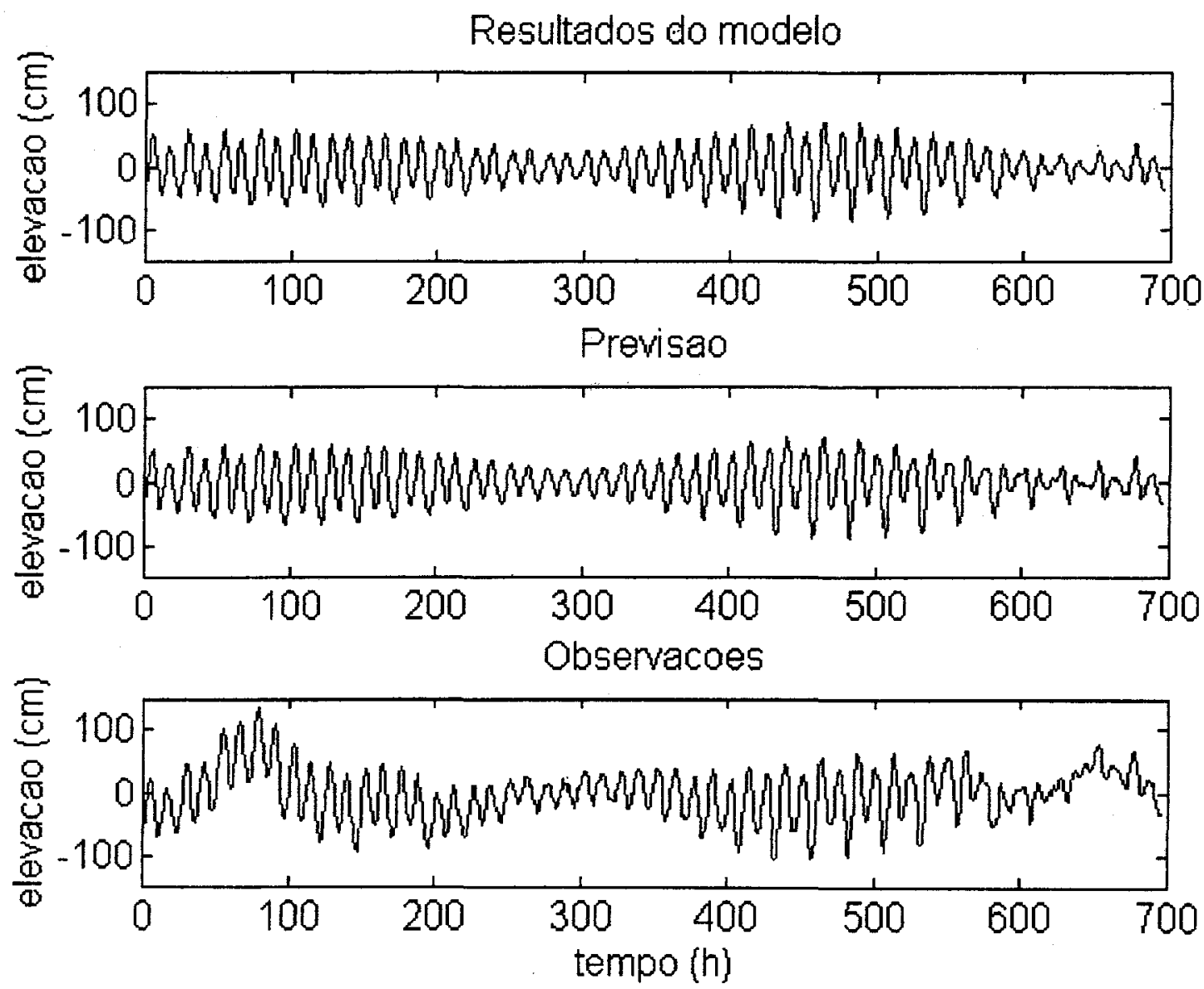

Fig. 8. Séries temporais de maré com resultados do modelo, previsão harmônica com 44 componentes e observações diretas, referentes a Torre Grande, no Porto de Santos (na grade - linha, coluna = 061, 084).

\section{Agradecimentos}

Os autores deste trabalho agradecem o apoio de diversas instituições, cientistas e técnicos na realização deste trabalho, em especial a: Instituto Oceanográfico da USP (IOUSP) e Instituto Astronômico e Geofísico da USP (IAGUSP), pelas facilidades de uso de computadores e pelo apoio de técnicos e docentes; Fundação de Amparo à Pesquisa do Estado de São Paulo (FAPESP) e Conselho Nacional de Desenvolvimento Científico e Tecnológico (CNPq), pelo Auxílio Pesquisa ao Projeto e pela cessão de Bolsas; Companhia Docas do Estado de São Paulo (CODESP), pela cessão de dados de maré do Porto de Santos; e Fundação de Estudos e Pesquisas Aquáticas (FUNDESPA), pela cessão de dados de correntes na Baía de Santos. Um agradecimento especial é extendido a Vanilde Ferreira de Oliveira, Telma Maria Pinheiro e Hemerson Everaldo Tonin, pela colaboração nos processamentos computacionais.

\section{Referências Bibliográficas}

Alfredini, P. 1994. Aspectos relativos a dinâmica hidráulica-salina do Baixo Rio Cubatão (Estado de São Paulo, Brasil). Santiago do Chile, Iahr. 12 p.

Blumberg, A. F. \& Mellor, G. L. 1987. A description of a three-dimensional coastal ocean circulation model. In: Heaps, N. S. ed. Three-dimensional coastal ocean models. Washington, American Geophysical Union, p. 1-16.

Camargo, R. \& Harari, J. 1994. Modelagem numérica de ressacas na plataforma sudeste do Brasil a partir de cartas sinóticas de pressão atmosférica na superficie. Bolm Inst. oceanogr., S Paulo, 42(1/2):19-34.

Castro Filho, B. M. 1985. Subtidal response to wind forcing in the South Brazil Bight during winter. Ph.D. Thesis. University of Miami. 211 p. 
Castro Filho, B. M.; Miranda, L. B. \& Miyao, S. Y. 1987. Condições hidrográficas na plataforma continental ao largo de Ubatuba: variações sazonais e em média escala. Bolm Inst. oceanogr., S Paulo, 35(2):135-151.

Cirano, M. \& Campos, E. J. D. 1996. Numerical diagnostic of the circulation in the Santos Bight with COROAS hydrographic data. Rev. bras. oceanogr., 44 (2): 105-121.

Franco, A. S. 1988. Tides - fundamentals, analysis and prediction. $2^{\mathrm{a}}$ ed. São Paulo, FCTH/USP. 249p.

Franco, A. S. \& Harari, J. 1987. Computer programs for tidal data checking, correction, analysis and prediction by the harmonic method. Relat. int. Inst. oceanogr. Univ. S Paulo, (16):1-65.

FUNDESPA - Fundação de Estudos e Pesquisas Aquáticas. 1996. Levantamento oceanográfico de parâmetros correntométricos e da estrutura termohalina na área do emissário submarino de Santos - Relatório de coleta de dados. $15 \mathrm{p}$.

FUNDESPA - Fundação de Estudos e Pesquisas Aquáticas. 1997. Levantamento oceanográfico da área diretamente afetada por efluentes dos emissários submarinos de esgotos da SABESP, entre os municípios de São Sebastião e Mongaguá, Estado de São Paulo (Projeto LOESS) - Campanha Emergencial na Praia da Enseada. Relatório Parcial. 179 p.

Galperin, B. \& Mellor, G. L. 1990. A timedependent, three-dimensional model of the Delaware Bay and River System. Part1: Description of the model and tidal analysis. Estuar. Coast. Shelf Sci., 31(3):231-253.

Harari, J. 1985. Desenvolvimento de um modelo numérico hidrodinâmico tri-dimensional linear, para a simulação e a previsão da circulação na plataforma brasileira, entre $23^{\circ}$ e $26^{\circ} \mathrm{S}$. Bolm Inst. oceanogr., 33(2):159-191.

Harari, J. \& Cacciari, P. L. 1995. Project for observing and modelling the circulation in the coastal area of Santos (SP, Brazil). Afro Am. Gloss News, 2(1):4-6.

Harari, J. \& Camargo, R. 1994. Simulação da propagação das nove principais componentes de maré na plataforma sudeste brasileira através de modelo numérico hidrodinâmico. Bolm Inst. oceanogr., 42(1/2):35-54.
Harari, J. \& Camargo, R. 1995. Tides and mean sea level variabilities in Santos (SP), 1944 to 1989. Relat. int. Inst. oceanogr. Univ. S Paulo, (36):115.

Mellor, G. L. 1993. User's Guide for a threedimensional, primitive equation, numerical ocean model. Princeton University, Internal Report. 35 p.

Mellor, G. L. \& Yamada, T. 1974. A hierarchy of turbulence closure models for planetary boundary layers. J. atmos. Sci., 31(7):1791-1806.

Mellor, G. L. \& Yamada, T. 1982. Development of a turbulence closure model for geophysical fluid problems. Rev. Gephys., 20:851-875.

Mesquita, A. R. 1974. Report on the seasonal variations of coastal waters, Brazil (lat $24^{\circ}$ ). Relat. int. Inst. oceanogr., Univ. S Paulo, (1):136.

Mesquita, A. R. 1983. Contribuição à oceanografia da região costeira sudeste do Brasil (Lat. $24^{\circ} \mathrm{S}$ ) Sub-projeto Hidrodinâmica Costeira: execução e resultados.- Tese de livre-docência. Universidade de São Paulo, Instituto Oceanográfico. $187 \mathrm{p}$.

Mesquita, A. R. \& Harari, J. 1983. Tides and tide gauges of Cananéia and Ubatuba - Brazil (lat. $24^{\circ}$ ). Relat. int. Inst. oceanogr. S Paulo, (11):114.

Mesquita, A. R. \& Harari, J. 1987. Harmonic constants of tides and currents of the Southern Brazilian Shelf. In: SIMPÓSIO SOBRE ECOSSISTEMAS DA COSTA SUL E SUDESTE BRASILEIRA: SÍNTESE DOS CONHECIMENTOS, Cananéia, 1987, São Paulo, ACIESP, 2:415-422.

Mesquita, A. R.; Leite, J. B. A. \& Rizzo, R. 1979 Contribuição ao estudo das correntes marinhas na plataforma entre Cabo Frio e Cananéia. Bolm Inst. oceanogr., 28(2):95-100.

Miranda, L. B. 1982. Análise de massas d'água da plataforma continental e da região oceânica adjacente: Cabo de São Tomé (RJ) a Ilha de São Sebastião (SP). Tese de livre-docência. Universidade de São Paulo, Instituto Oceanográfico. $123 \mathrm{p}$.

O'Connor, W. P. 1991. A numerical model of tides and storm surges in the Rio de la Plata Estuary. Continent. shelf Res., 11(12):1491-1508. 
Oey, L. Y.; Mellor, G. L. \& Hires, R. I. 1985. Tidal modelling of the Hudson - Raritan Estuary. Estuar. Coast. shelf Sci., 20(5):511-527.

Oey, L. Y.; Mellor, G. L. \& Hires, R. I. - 1985a. A three-dimensional simulation of the Hudson Raritan Estuary. Part I: Description of the model and model simulations. J. phys. Oceanogr., 15(12):1676-1692.

Sondotécnica/INPH. 1977. Comportamento Hidráulico e Sedimentológico do Estuário Santista. Relatório Técnico. $2 \mathrm{v}$.

Stacey, M. W.; Pond, S. \& Nowak, Z. P. 1995. A numerical model of the circulation in Knight Inlet, British Columbia, Canada, J. phys. Oceanogr., 25(6):1037-1062.
Stech, J. L. \& Lorenzzetti, J. A. 1992. The response of the South Brazil Bight to the passage of wintertime cold fronts. J. geoph. Res., 97(C6):9507-9520.

Yassuda, E. A. 1991. Modelo numérico do transporte de sedimentos no canal principal do estuário de Santos. Dissertação de mestrado. Universidade de São Paulo, Instituto Oceanográfico. 122 p.

(Manuscrito recebido 15 agosto 1997; revisado 15 abril 1998; aceito 20 agosto 1998) 